\title{
To what extent can aerosol water explain the discrepancy between model calculated and gravimetric $\mathbf{P} \mathbf{M}_{10}$ and $\mathbf{P M}_{2.5}$ ?
}

\author{
S. G. Tsyro \\ Norwegian Meteorological Institute, Oslo, Norway \\ Received: 13 July 2004 - Published in Atmos. Chem. Phys. Discuss.: 29 September 2004 \\ Revised: 20 January 2005 - Accepted: 9 February 2005 - Published: 16 February 2005
}

\begin{abstract}
Inter-comparisons of European air quality models show that regional transport models, including the EMEP (Co-operative Programme for monitoring and evaluation of the long-range transmission of air pollutants in Europe) aerosol model, tend to underestimate the observed concentrations of $\mathrm{PM}_{10}$ and $\mathrm{PM}_{2.5}$. Obviously, an accurate representation of the individual aerosol constituents is a prerequisite for adequate calculation of PM concentrations. On the other hand, available measurements on the chemical characterization of ambient particles reveal that full chemical PM mass closure is rarely achieved. The fraction unaccounted for by chemical analysis can comprise as much as $30-40 \%$ of gravimetric $\mathrm{PM}_{10}$ or $\mathrm{PM}_{2.5}$ mass. The unaccounted PM mass can partly be due to non-C atoms in organic aerosols and/or due to sampling and measurement artefacts. Moreover, a part of the unaccounted PM mass is likely to consist of water associated with particles. Thus, the gravimetrically measured particle mass does not necessarily represent dry $\mathrm{PM}_{10}$ and $\mathrm{PM}_{2.5}$ mass. This is thought to be one of the reasons for models under-prediction of observed PM, if calculated dry $\mathrm{PM}_{10}$ and $\mathrm{PM}_{2.5}$ concentrations are compared with measurements. The EMEP aerosol model has been used to study to what extent particle-bound water can explain the chemically unidentified PM mass in filter-based particle samples. Water content of $\mathrm{PM}_{2.5}$ and $\mathrm{PM}_{10}$ has been estimated with the model for temperature $20^{\circ} \mathrm{C}$ and relative humidity $50 \%$, which are conditions required for equilibration of dust-loaded filters according to the Reference method recommended by the European Committee for Standardization (CEN). Model calculations for Europe show that, depending on particle composition, particle-bound water constitutes $20-35 \%$ of the annual mean $\mathrm{PM}_{10}$ and $\mathrm{PM}_{2.5}$ concentrations, which is consistent with existing experimental estimates. At two Austrian sites, in Vienna and Streithofen, where daily measure-
\end{abstract}

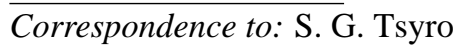

(svetlana.tsyro@met.no) ments of $\mathrm{PM}_{2.5}$ mass and chemical composition are available, calculated $\mathrm{PM}_{2.5}$ water content is found to be about 75 $80 \%$ of the undetermined $\mathrm{PM}_{2.5}$ mass and there is correlation between them. Furthermore, accounting for aerosol water has improved the agreement between modelled and measured daily $\mathrm{PM}_{2.5}$ concentrations, whilst model calculated dry $\mathrm{PM}_{2.5}$ concentrations appear to agree quite well with the total identified $\mathrm{PM}_{2.5}$ mass. No information on the composition of PM measured at EMEP sites is presently available. Given that $\mathrm{PM}_{10}$ and $\mathrm{PM}_{2.5}$ concentrations are measured at EMEP stations with gravimetric methods they are likely to contain water. We show that the levels of modelled $\mathrm{PM}_{10}$ and $\mathrm{PM}_{2.5}$ concentrations with aerosol water included agree with measurements better than dry PM concentrations. As expected, the spatial correlation has not changed significantly, whereas the temporal correlation of daily $\mathrm{PM}_{10}$ and $\mathrm{PM}_{2.5}$ with monitoring data has slightly improved at most of the EMEP sites. Our results suggest that aerosol water should be accounted for in modelled $\mathrm{PM}_{10}$ and $\mathrm{PM}_{2.5}$ when compared with filter-based gravimetric measurements.

\section{Introduction}

The main purpose of EMEP (Co-operative Programme for monitoring and evaluation of the long-range transmission of air pollutants in Europe) models is to support policy design for trans-boundary air pollution in Europe. Therefore, the models are required to provide reliable information on the long-range transport and the level of regional concentrations and depositions of relevant pollutants. In line with this, the EMEP aerosol model is expected to produce reliable calculations of the concentrations of particulate matter (PM) in order to facilitate the assessment of adverse health effects associated with particulate pollutants. Validation of the EMEP aerosol model involves regular comparison of calculated concentrations of policy relevant metrics $\mathrm{PM}_{2.5}$ and

(C) 2005 Author(s). This work is licensed under a Creative Commons License. 
$\mathrm{PM}_{10}$ with measurements from the EMEP monitoring network. Recently, measurement data available from EIONET (European Environment Information and Observation Network) and from national (Austrian, Spanish and Norwegian) monitoring networks and research projects have been employed for the model evaluation.

In previous studies (e.g. Tsyro, 2003), the EMEP aerosol model was found to systematically underestimate observed $\mathrm{PM}_{2.5}$ and $\mathrm{PM}_{10}$ concentrations by $40-60 \%$ on average, when dry $\mathrm{PM}_{2.5}$ and $\mathrm{PM}_{10}$ masses from the model were compared with measurements. The model underestimation of observed PM concentrations was partly explained by that such important aerosol components as secondary organic aerosols (SOA) and wind blown and re-suspended dust, was not yet implemented in the model. This means that the model simulations did not complete the mass closure of $\mathrm{PM}_{2.5}$ and $\mathrm{PM}_{10}$.

On the other hand, data on $\mathrm{PM}_{2.5}$ and $\mathrm{PM}_{10}$ measurements supplemented with analyses of the particle chemical composition (e.g. Balasubramanian et al., 2003; Matta et al., 2003; Putaud et al., 2004; Zappoli et al. 1999; Yttri, 2003) reveal that full chemical mass closure is rarely achieved, and there is often a discrepancy between chemical and gravimetric masses. In other words, after all important aerosol components (inorganic and carbonaceous compounds, minerals and metals) are analysed a part of PM mass remains unidentified. The possible sources for the discrepancy between gravimetric PM mass and the total mass of all identified components are associated with: 1) non-C atoms, i.e. oxygen, hydrogen, nitrogen, in organic aerosol, 2) particle-bound water and 3) measurement artefacts. In this paper, we will focus on the role of particle water in PM mass. Accounting for water absorbed by collected particles on the filter tape of the Betagauge was discussed in Chang and Tsai (2003) and Chang et al. (2001). In the work by Neusüß et al. (2002), the mass of water associated with hygroscopic aerosol compounds, was derived from the measured particles growth factor and was estimated to be about $20-25 \%$ of $\mathrm{PM}_{10}$ mass at $60 \%$ relative humidity. In the same work, particle chemical mass concentrations including water were shown to correspond fairly well with the gravimetric mass concentrations.

Filter-based gravimetric methods are recommended by EMEP and EU Council for determining $\mathrm{PM}_{10}$ mass concentrations at monitoring sites. In accordance with the Reference Method developed by the European Committee for Standardization (CEN), the filters should be equilibrated at about $50 \%$ relative humidity and $20^{\circ} \mathrm{C}$ temperature before they are weighed, both prior to the sample collection and after sampling. Gravimetrically determined PM mass will also include the mass of liquid water associated with particles.

The purpose of this work is to estimate with a model to what extent aerosol water can explain the unaccounted fraction of gravimetric PM mass. For this purpose, the EMEP aerosol model has been used. We also examine how accounting for particle-bound water improves the comparison of model calculated $\mathrm{PM}_{10}$ and $\mathrm{PM}_{2.5}$ with observations. Firstly, a short description is given of the EMEP aerosol model. We also briefly explain the CEN Reference method recommended by EU and EMEP for measuring PM mass. Then, the main results from model verification with respect to $\mathrm{PM}_{10}$ and $\mathrm{PM}_{2.5}$ are outlined and problems related to the interpretation of comparison/disagreement between calculations and measurements are identified. Further, the model estimates of water content in $\mathrm{PM}_{10}$ and $\mathrm{PM}_{2.5}$ at the conditions required for filter equilibration are presented. Daily measurements of $\mathrm{PM}_{2.5}$ concentrations and chemical composition available at two Austrian stations have been employed for more elaborate testing of model calculations of particle-bound water, dry and wet $\mathrm{PM}_{2.5}$ mass. Finally, assuming that gravimetrically measured PM mass at EMEP sites includes particle-bound water, we compare model simulated wet (including water) $\mathrm{PM}_{10}$ and $\mathrm{PM}_{2.5}$ concentrations with EMEP measurements. Summary and conclusions are given in the end.

\section{The EMEP aerosol model}

Below, a brief description of the EMEP aerosol model is given. Previous model versions have been described in Tsyro (2002), with a detailed model description of the latest version in Appendix A in Simpson et al. (2003).

\subsection{Short model description}

The EMEP aerosol model describes the emissions, chemical transformations, transport and dry and wet removal of atmospheric aerosol and calculates the size-aggregated aerosol number and mass and particle chemical composition. The particle size distribution is resolved with four monodisperse size modes, i.e. nucleation, Aitken, accumulation and coarse mode. The aerosol chemical composition is described with seven components: sulphate $\left(\mathrm{SO}_{4}^{2-}\right)$, nitrate $\left(\mathrm{NO}_{3}^{-}\right)$, ammonium $\left(\mathrm{NH}_{4}^{+}\right)$, elemental (EC) and organic (OC) carbon, sea salt $(\mathrm{NaCl})$ and mineral dust, which are assumed to be internally mixed. In this way, all particles in the same mode are assumed to have the same size and chemical composition. Aerosol associated water is a diagnostic parameter and calculated in the model for each size mode. The aerosol dynamics module MM32 (Pirjiola et al., 2003) is employed to calculate particle coagulation and condensational growth. The empirical parameterisation by Berndt et al., 2000 for binary nucleation rate of $\mathrm{H}_{2} \mathrm{SO}_{4}-\mathrm{H}_{2} \mathrm{O}$ is currently used in the EMEP aerosol model.

The model accounts for primary and secondary aerosols. In the model, primary aerosols originate from both anthropogenic and natural sources. Primary anthropogenic emissions of $\mathrm{PM}_{10}$ and $\mathrm{PM}_{2.5}$ are based on the TNO CEPMEIP inventory (TNO, 2001) scaled as far as possible with the national totals of PM emission reported to EMEP (Vestreng, 2003). As no information on the chemical and size speciation of PM emissions has been available, rather crude 
assumptions have been used in the model to characterise chemical composition and size distribution of PM emissions. $\mathrm{PM}_{2.5}$ emissions have been distributed between $\mathrm{OC}$, EC and mineral dust, and between the Aitken and accumulation modes, and the coarse PM emissions have been assumed to consist of mineral dust. The primary natural PM in the model includes presently sea salt aerosol, for which the formation rates are calculated following Monahan (1978) and Mårtinsson et al. (2002). Implementation in the EMEP model of natural mineral dust due to wind erosion and resuspension is in progress, but not included in the results presented here.

Secondary aerosols in the model are formed from the anthropogenic emissions of gaseous precursors, $\mathrm{SO}_{\mathrm{x}}, \mathrm{NO}_{\mathrm{x}}$ and $\mathrm{NH}_{3}$, as a result of homogeneous and heterogeneous chemical transformations. Gas/aerosol partitioning of semivolatile inorganic components is calculated with the Equilibrium Simplified Aerosol Model, EQSAM, (Metzger et al., 2002a). The EQSAM used in the EMEP model currently treats the equilibrium in $\mathrm{SO}_{4}^{2-}-\mathrm{HNO}_{3}-\mathrm{NO}_{3}^{-}-\mathrm{NH}_{3}-\mathrm{NH}_{4}^{+}-$ $\mathrm{Na}^{+}-\mathrm{Cl}^{-}$system. Several schemes to calculate the formation of secondary organic aerosols (SOA) from biogenic and anthropogenic sources have been tested (Andersson-Sköld and Simpson, 2001; Simpson and Makar, 2004), but SOA is not included presently in the aerosol model.

Aerosol water is calculated with EQSAM based on the aerosol chemical composition. At each time-step, particle diameter is calculated from the total (i.e. dry PM plus water) particle mass and the particle number concentration in each size mode. The parameterisation of particle dry deposition is based on the resistance approach, where the sublaminar layer resistance is calculated dependent on the particle size and the type of land-use. The scheme for aerosol wet deposition employs the size dependent scavenging ratios for in-cloud and sub-cloud scavenging. In clouds, all accumulation mode particles are assumed to become activated. A rather simple approach is presently implemented in the model to account for the in-cloud activation and growth of Aitken particles (Fitzgerald, 1973; Hansson, person. commun.). The detailed model description can be found in Appendix A in Simpson et al. (2003) and on the EMEP website at http://www.emep.int.

\subsection{Aerosol water in the EMEP aerosol model}

The aerosol water content is calculated with the EQSAM model based on the semi-empirical so-called ZSR-relation after Zdanovski (1948) and Stokes and Robinson (1966), which assumes that the water activity of the mixed solute is equal to the water activity of all single-solute solutions. Thus, the water content associated with a mixed solution is the sum of the water content of all binary solutions. Then, the mass of aerosol liquid water content $(L W C)$ is found as the sum:

$L W C=\sum_{i}^{N}\left(M_{i} / m_{i}\right)$,

where $L W C(\mathrm{~kg} / \mathrm{m})^{3}$ is the liquid water content of aerosol, $N$ is the total number of single-salt solutions, $M_{i}\left(\mathrm{~mol} / \mathrm{m}^{3}\right)$ is the molar concentration and $m_{i}(\mathrm{~mol} / \mathrm{kg})$ is the molality of salt $i$. The single-solute molalities are parameterized in terms of relative humidity (detailed description can be found in Metzger et al., 2002 and Metzger, 2000).

The version of EQSAM adopted in the EMEP model assumes meta-stable aerosols, i.e. that aqueous aerosols remain in a meta-stable phase. This implies that calculated aerosol water represents the upper branch of the hysteresis curve. This is believed to be rather typical for most of the measurement conditions when the end of filter exposure is in the morning. However, in some cases when the ambient humidity is much lower than that in the conditioning room (i.e. $50 \%$ ), collected particles will absorb water following the lower branch of the hysteresis curve. In such cases, the model may overestimate the water content of the particle sample. The soluble aerosol compounds in the aerosol model are $\mathrm{SO}_{4}^{2-}, \mathrm{NO}_{3}^{-}, \mathrm{NH}_{4}^{+}$and sea salt. Soluble aerosol compounds, accounted for in the aerosol model, are $\mathrm{SO}_{4}^{2-}, \mathrm{NO}^{3-}, \mathrm{NH}^{4+}$ and sea salt, while organic aerosols are presently assumed to be insoluble. Because of the latter assumption, an underestimation of aerosol water can be expected, as a significant fraction of OC can be water soluble (e.g. Putaud et al., 2003; Balasubramanian et al., 2003; Matta et al., 2003). However, this assumption is not expected to change the main results presented here because the mass OC in PM is considerably underestimated by the model as it does not include SOA (see above).The calculated aerosol water content will depend on the mass of soluble aerosol compounds and on the type of salt mixture in particles.

\section{Measurements of PM mass}

\subsection{EMEP/EU guidelines for $\mathrm{PM}_{10}$ measurements}

To establish the basis for $\mathrm{PM}_{10}$-monitoring a reference method has been developed by the European Committee for Standardization (CEN). The Reference Method described in CEN standard EN 12341 "Air Quality - Field Test Procedure to Demonstrate Reference Equivalence of Sampling Methods for the PM10 fraction of particulate matter" was adopted by CEN in November 1998 (EN 12341, 1998). The method consists of a PM10 sampling inlet coupled with a filter substrate and a regulated flow device. The mass collected on the filter is determined gravimetrically by means of a microbalance under well defined environmental conditions. No European Reference Method has been established up to now for the measurements of $\mathrm{PM}_{2.5}$. This standard is currently being 
developed by CEN under mandate of the European Commission (Second Position Paper, 2003).

EU Council Directive 1999/30/EC defines the reference method for the sampling and measurement of $\mathrm{PM}_{10}$ to be the one described in EN 12341. However, a Member State may use any other method which gives results equivalent to the reference method or displays a consistent relationship to the reference method. The EMEP manual on $\mathrm{PM}_{10}$ measurements (EMEP/CCC, 2001) adopted in 2002 states that the aerosol particulate mass should preferably be determined according to EN 12341 (1998), or other methods and/or instruments if proven to provide results consistent with the reference method. All of the sites currently reporting $\mathrm{PM}_{10}$ and $\mathrm{PM}_{2.5}$ concentrations to EMEP use gravimetric methods, otherwise Beta-gauges (Beta Attenuation Monitors) and TEOM (Tapered Elements Oscillating Microbalance) instruments are still the most commonly used methods to monitor PM mass in European national networks.

When gravimetric methods are used for PM mass measurements, the daily samples collected on filters are transferred to the laboratory for conditioning, weighing and subsequent chemical analyses. As required by EN 12341, the filters should be equilibrated at $20^{\circ} \mathrm{C}( \pm 1)$ and $50 \%$ relative humidity $( \pm 5)$ for $48 \mathrm{~h}$. This equilibration should be performed before the filters are weighed prior to the sample collection, and after sampling, before the filter is weighed again with the collected sample. As pointed out above, the equilibrated filters will contain some amount of liquid water associated with particles, so that the gravimetrically determined $\mathrm{PM}_{10}$ and $\mathrm{PM}_{2.5}$ concentrations do not typically represent PM dry mass. On the other hand, automated instruments for PM monitoring, like TEOM or Beta-gauge, either use heated inlets or other equipment (e.g. diffusion dryer in TEOM) in order to remove moisture from the sample. Thus, the automatically monitored PM concentrations will be much closer to representing dry aerosol mass than gravimetric PM mass.

\subsection{Particle water in gravimetric PM mass}

Available data on PM mass measurements, supplemented with analysis of PM chemical composition, and results of mass closure experiments presented in a number of publications, reveal that full chemical characterisation of particles is rarely achieved. There is typically a difference between the gravimetric PM mass concentration and the sum of all chemically identified components. The unaccounted part of PM mass could be as large as $25-35 \%$ of the $\mathrm{PM}_{10}$ and $\mathrm{PM}_{2.5}$ mass.

It was already pointed out above, that besides sampling and analysis artefacts affecting the attainment of chemical mass balance, the unaccounted mass can partly be explained by elements associated with organic aerosols other than carbon. Moreover, a part of the unaccounted PM mass is commonly attributed to particle-bound water. Estimates based on the growth factor measurements show that for instance
$\left(\mathrm{NH}_{4}\right)_{2} \mathrm{SO}_{4}$ can contain about $30 \%$ (mass) of water at $50 \%$ relative humidity (Schwela et al., 2002). Studies of the water uptake by particles on filters exposed to different humidities (Winkler and Junge, 1972) show the increase of particle mass at relative humidity of $50 \%$ to be $10-30 \%$ compared to the dry mass. Results from several studies, summarised in Schwela et al. (2002), support those findings. Further more, the amount of water in PM samples will vary for different samples and measurement sites, depending on the particle composition and the ambient relative humidity and temperature (e.g. Warneck, 2000). Depending on the ambient conditions during sampling, particles on the dust-loaded filter can either adsorb or lose water under post-equilibration. The relationship between particle mass and composition and particle water content is rather complicated due to hysteresis in the water adsorption-desorption pathways (i.e. the deliquescence and crystallization relative humidity points of the aerosol particle do not coincide). Due to the hysteresis phenomenon, the mass of water will be greater in particle samples collected at high ambient humidity and then transferred to a lower humidity environment in the laboratory, as compared to the opposite case.

\section{Model calculations and comparison with measure- ments}

\subsection{Calculations of dry PM concentrations}

The EMEP aerosol model, without any accounting for PMwater, was previously compared for the years 1999-2001 with data available from the EMEP monitoring network, the AIRBASE database and several national research campaigns (Tsyro, 2003; Tsyro et al., 2003). The model was found to systematically underestimate measured $\mathrm{PM}_{2.5}$ and $\mathrm{PM}_{10}$ concentrations by $40-60 \%$ on average (as shown in Fig. 9, upper panels), when dry $\mathrm{PM}_{10}$ and $\mathrm{PM}_{2.5}$ concentrations were compared with measurements. These discrepancies between model calculations and measurements were explained in terms of the lack of secondary organic aerosols (SOA) and wind blown and re-suspended dust. For instance, the largest underestimations of $\mathrm{PM}_{10}$ and $\mathrm{PM}_{2.5}$ by the model were found at Spanish stations. This is because of the significant contribution of mineral dust to PM in Spain due to wind soil erosion and Saharan dust intrusions (Rodríguez et al., 2001; Rodríguez et al., 2002).

Particulate matter is not a single pollutant, but a complex mixture of many pollutants. Therefore, the adequate model calculation of $\mathrm{PM}_{10}$ and $\mathrm{PM}_{2.5}$ depends on its accurate representation of the individual PM constituents. Unfortunately, model evaluation with respect to the individual aerosol components is presently hampered by the lack of data on particle chemical composition. Data on particle chemical characterisation, necessary for elaborating the model verification, was not available at the same EMEP and AIRBASE monitoring 
Table 1. Overview of the stations where measurements were available of both PM mass and chemical composition.

\begin{tabular}{cccccc}
\hline Country & Station & Station code & Coordinates & Measurement period & Resolution \\
\hline Norway & Birkenes & NO01 & $58^{\circ} 23^{\prime} \mathrm{N}$ & 1 Jan.- & Daily SIA \\
& (EMEP) & & $8^{\circ} 15^{\prime} \mathrm{E}$ & 31 Dec. 2001 & weekly OC/EC \\
Austria & Wien & AU01 & $48^{\circ} 13^{\prime} \mathrm{N}$ & 1 June 1999- & Daily \\
& (urban) & & $16^{\circ} 21^{\prime} \mathrm{E}$ & 31 May 2000 & \\
& Streithofen & AU02 & $48^{\circ} 16^{\prime} \mathrm{N}$ & 1 June 1999- & Daily \\
& (rural) & & $15^{\circ} 56^{\prime} \mathrm{E}$ & 31 May 2000 & \\
\multirow{5}{*}{ Spain } & Monagrega & & $40^{\circ} 57^{\prime} \mathrm{N}$ & 24 Mar. $1999-$ & Daily \\
& (rural) & & $0^{\circ} 17^{\prime} \mathrm{W}$ & 29 June 2000 & (intermittent) \\
& Bemantes & & $20^{\circ} 15^{\prime} \mathrm{N}$ & 8 Jan.- & \\
& (rural) & & $8^{\circ} 11^{\prime} \mathrm{W}$ & 27 Dec. 2001 & \\
& Montseny & & $41^{\circ} 46^{\prime} \mathrm{N}$ & 22 Mar.- & \\
& (rural) & $2^{\circ} 21^{\prime} \mathrm{E}$ & 29 Aug. 2001 & \\
\hline
\end{tabular}

sites where $\mathrm{PM}_{10}$ and $\mathrm{PM}_{2.5}$ concentrations were measured, except for one site in Birkenes, Norway (Table 1).

Thus, there was insufficient information for drawing conclusions on the reasons for the discrepancies between modelled and measured PM concentrations. Recently, measurements of $\mathrm{PM}_{10}$ and $\mathrm{PM}_{2.5}$ chemical composition from Spanish and Austrian national networks and research campaigns (Rodrîguez et al., 2002; Querol, personal commun.; and Puxbaum et al., 2003) have been made available to us (Table 1). These data have been used for evaluating the revised model results in this work.

In Tsyro (2003), model calculated annual mean $\mathrm{PM}_{10}$ chemical compositions were compared with data on aerosol chemical characterization synthesized in Putaud et al. (2004). Model predictions of the annual mean concentrations of secondary inorganic aerosols (SIA), namely $\mathrm{SO}_{4}^{2-}, \mathrm{NO}_{3}^{-}$and $\mathrm{NH}_{4}^{+}$, were generally in reasonable agreement with the measured concentrations (examples for rural stations are presented in Fig. 1). As expected, the model considerably underestimated concentrations of organic carbon (OC) as only primary anthropogenic OC was taken into account in the calculations. At some sites, especially in Spain, the model also underestimated mineral dust concentrations because wind blown and re-suspended dust was not implemented in the aerosol model. On the other hand, the uncertainties associated with anthropogenic PM emissions and, in particular, with their chemical speciation were recognised to be an important source of discrepancies between modelled and measured concentrations of carbonaceous and mineral aerosol components.

It was emphasized that improvement in the quality of PM emission data and its chemical speciation as well as the further model development to account for all important aerosol components were prerequisites for the accurate modelling of PM chemical composition. However, the question remains: would the model, providing its adequate calculation of the individual aerosol components, be able of reproducing the monitored $\mathrm{PM}_{10}$ and $\mathrm{PM}_{2.5}$ concentrations? As discussed above, a part of the unidentified PM mass can probably be attributed to aerosol water. At present, particle-bound water is not measured operationally at the stations where PM is monitored. If PM mass alone is measured with filter-based gravimetric methods it appears impracticable to derive dry PM mass for appropriate model verification from the measured PM concentrations. Instead, in this work we use the model to estimate the amount of water remaining on particles after the filter conditioning and then, to account for the residual water in calculated $\mathrm{PM}_{10}$ and $\mathrm{PM}_{2.5}$ concentrations when comparing them with observations.

\subsection{Model calculations of particle-bound water}

\subsubsection{Annual mean PM water content}

Water content of $\mathrm{PM}_{10}$ and $\mathrm{PM}_{2.5}$ has been calculated with the model for the conditions which are required according to the Reference Method for sample equilibration, i.e. temperature of $20^{\circ} \mathrm{C}$ and relative humidity of $50 \%$. Calculated in this way PM water content represents particle-bound water (henceforth also referred to as residual water) still present in gravimetric $\mathrm{PM}_{10}$ and $\mathrm{PM}_{2.5}$ concentrations after the sample conditioning. Figure 2 shows the maps of model calculated annual mean mass of residual $\mathrm{PM}_{10}$ water and the fraction of water in "wet" $\mathrm{PM}_{10}$ concentrations for 2001. According to our model simulations, gravimetrically measured annual mean $\mathrm{PM}_{10}$ concentrations can contain between $0.5 \mu \mathrm{g} / \mathrm{m}^{3}$ water in Scandinavia and $6.5 \mu \mathrm{g} / \mathrm{m}^{3}$ water in the Netherlands and Belgium. The calculated annual mean mass of residual water associated with $\mathrm{PM}_{2.5}$ varies between 0.3 and $5 \mu \mathrm{g} / \mathrm{m}^{3}$. Particle water content is determined by the mass fraction and 

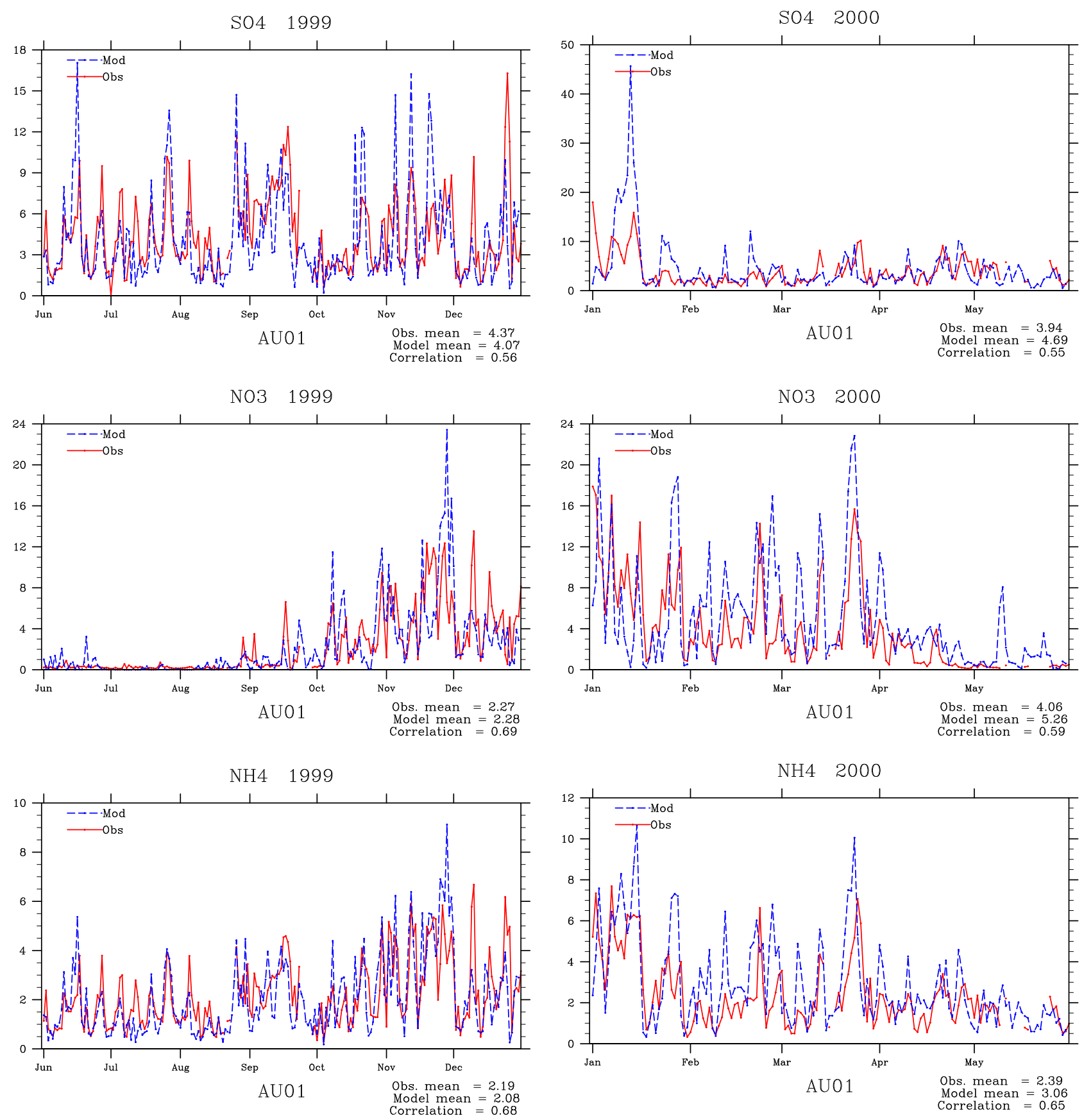

Fig. 1. Chemical composition of $\mathrm{PM}_{10}$ and rural stations: calculated with the EMEP aerosol model vs. measured (from Putaud et al., 2004). In the measurements, ND - denotes the unidentified PM fraction.

the type of mixture of soluble PM constituents. Thus, the geographical distribution of calculated residual aerosol water reflects the distribution of soluble aerosols, which in the model are sulphate, nitrate, ammonium and sea salt. Organic aerosols have been assumed insoluble. Because secondary inorganic components are mainly in the fine mode the water content of $\mathrm{PM}_{10}$ and $\mathrm{PM}_{2.5}$ is rather similar in most inland areas. There is a noticeable increase in the mass of particlebound water found in the coastal areas due to the contribution of sea salt particles.

According to the model estimates, the fraction of residual water varies across Europe between about 20 and $40 \%$ (largely 20-30\%) in $\mathrm{PM}_{10}$ and between 20 and 35\% in $\mathrm{PM}_{2.5}$, depending on the fraction of soluble components. 

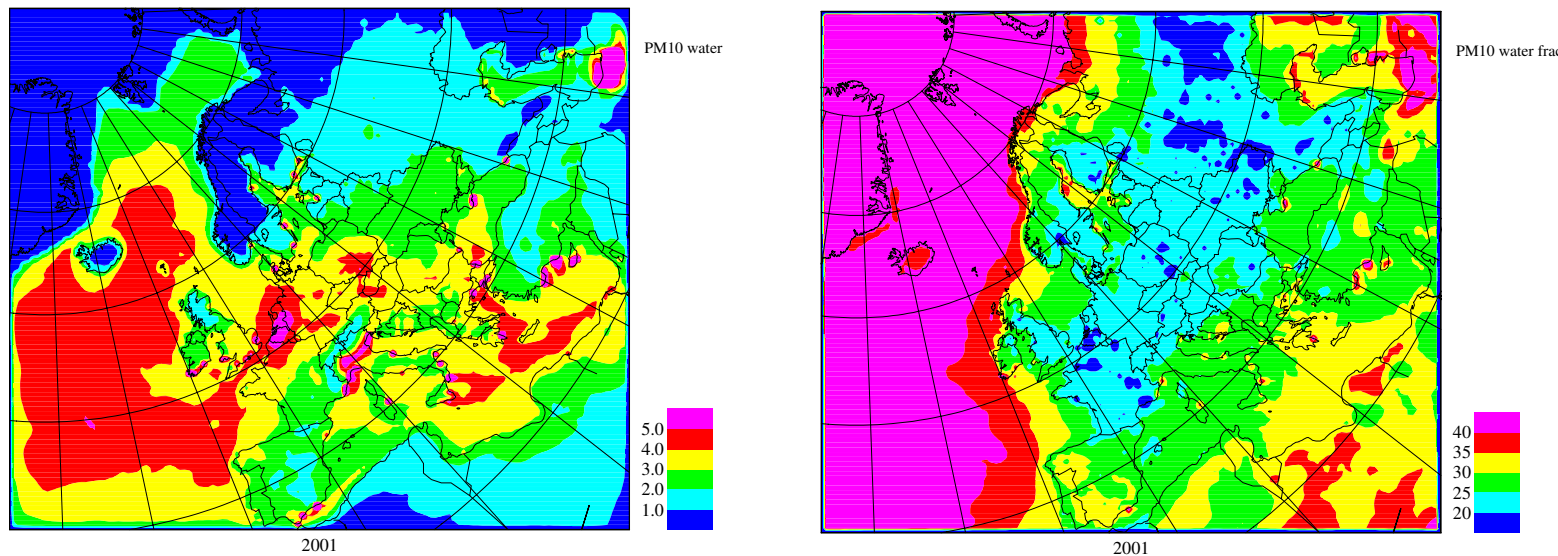

Fig. 2. Model calculated (a) mass (in $\mu \mathrm{g} / \mathrm{m}^{3}$ ) of particle water and (b) water fraction (\%) in PM10 (water contributions calculated for $20^{\circ} \mathrm{C}$ and 50\% RH. Year: 2001).

The lowest fraction of residual water in $\mathrm{PM}_{10}$ mass (below 20\%) has been calculated for parts of Russia, where the calculated fraction of insoluble primary particles (EC, OC, mineral dust) in $\mathrm{PM}_{10}$ is largest (30-50\%). The calculated distribution of residual water fraction in $\mathrm{PM}_{2.5}$ is rather similar to that in $\mathrm{PM}_{10}$. The largest differences in water content of $\mathrm{PM}_{10}$ and $\mathrm{PM}_{2.5}$ are calculated in coastal areas due to the contribution of water associated with coarse sea salt particles. Our calculations of $\mathrm{PM}_{10}$ and $\mathrm{PM}_{2.5}$ water content at $50 \%$ relative humidity seem to be in an agreement with results from other relevant studies (e.g. Neusüß et al., 2002) and are believed to be a rather reasonable estimate of residual particle water.

Figure 3 compares the annual mean chemical composition of $\mathrm{PM}_{10}$ and $\mathrm{PM}_{2.5}$ calculated with the EMEP aerosol model with measurements at stations in Spain, Austria and Norway. Here, purple colour designates both the undetermined fraction in measured PM mass (ND) and the residual particlebound water in the model results. As expected, model calculated $\mathrm{PM}_{10}$ and $\mathrm{PM}_{2.5}$ concentrations agree better with the measured values when residual water in PM is accounted for. Figure 3 indicates that the main reason for model underestimation of $\mathrm{PM}_{10}$ and $\mathrm{PM}_{2.5}$ is its underestimation of the concentrations of carbonaceous particles and mineral dust in Spain.

At all considered sites, the mass of residual water calculated with the model is smaller than the unaccounted mass in measured $\mathrm{PM}_{10}$ and $\mathrm{PM}_{2.5}$ (Fig. 3 and Table 2). According to the calculation results, water in $\mathrm{PM}_{10}$ and $\mathrm{PM}_{2.5}$ can explain 30 to $80 \%$ of the unaccounted mass. Since aerosol water was not measured at those sites it was impracticable to validate the model calculations of residual $\mathrm{PM}_{10}$ and $\mathrm{PM}_{2.5}$ water.

The calculation results in this section suggest the following:

1. The model seems to give a reasonable estimate of the mass of water in $\mathrm{PM}_{10}$ and $\mathrm{PM}_{2.5}$ at $50 \%$ relative humidity. Accurate calculation of the mass of soluble components, in this case $\mathrm{SO}_{4}^{2-}, \mathrm{NO}_{3}^{-}$and $\mathrm{NH}_{4}^{+}$, is a prerequisite for the good prediction of water content.

2. The residual particle water can explain a part of the undetermined PM mass (30-80\% according our estimates), while the other, more variable part on the undetermined PM mass is probably due to other factors, e.g. non-C atoms associated with organic aerosols and/or the measurement artefacts (as discussed in Putaud et al., 2004; Yttri, 2003).

However, more measurements on PM mass and chemical composition and, in particular, measurements of particle water are needed for further testing and verification of those results.

\subsubsection{Testing model results with daily data at two Austrian} sites

At the sites shown in Fig. 3, the fraction of undetermined PM mass averaged over longer (6-12 months) periods is around 20-35\%. However, for daily $\mathrm{PM}_{2.5}$ and $\mathrm{PM}_{10}$ the unaccounted fraction varied from below 0 to $75-80 \%$ (negative values occurred in several cases were probably due to the measurement artefacts). Measurement data with a daily resolution on gravimetric $\mathrm{PM}_{2.5}$ concentrations and $\mathrm{PM}_{2.5}$ chemical composition was only available at two Austrian sites, Vienna and Streithofen, for the period 1 May 1999-31 May 2000. We have used these data in order to see if a correspondence can be found between daily variations of model calculated $\mathrm{PM}_{2.5}$ water, on the one hand, and $\mathrm{PM}_{2.5}$ unaccounted mass in observations, on the other hand. Below, we present results for 2000 , while the analysis and conclusions have been based on the data from both 1999 and 2000.

Model calculated and measured chemical composition of $\mathrm{PM}_{2.5}$ at Vienna site (AU01) and Streithofen site (AU02), 
Table 2. Unaccounted mass in measured $\mathrm{PM}_{10}$ and mass of modelled residual aerosol water in $\mathrm{PM}_{10}\left(\mathrm{PM}_{2.5}\right.$ at Montseny) and their fractions with respect to the mass of soluble PM (SIA+marine).

\begin{tabular}{ccccccc}
\hline & Bemantes & Monagrega & Montseny & NO01 & AU01 & AU02 \\
\hline ND $\left(\mu \mathrm{g} / \mathrm{m}^{3}\right)$ & 3.5 & 5.86 & 5.97 & 1.68 & 8.43 & 5.9 \\
ND/soluble PM & 0.50 & 0.78 & 1.12 & 0.55 & 0.73 & 0.55 \\
& & & & & & \\
Mod. water $\left(\mu \mathrm{g} / \mathrm{m}^{3}\right)$ & 3.01 & 2.39 & 2.57 & 1.13 & 4.11 & 3.8 \\
Water/soluble PM & 0.47 & 0.41 & 0.41 & 0.39 & 0.39 & 0.41 \\
\hline
\end{tabular}

PM10 and PM2.5 chemical composition, Spain

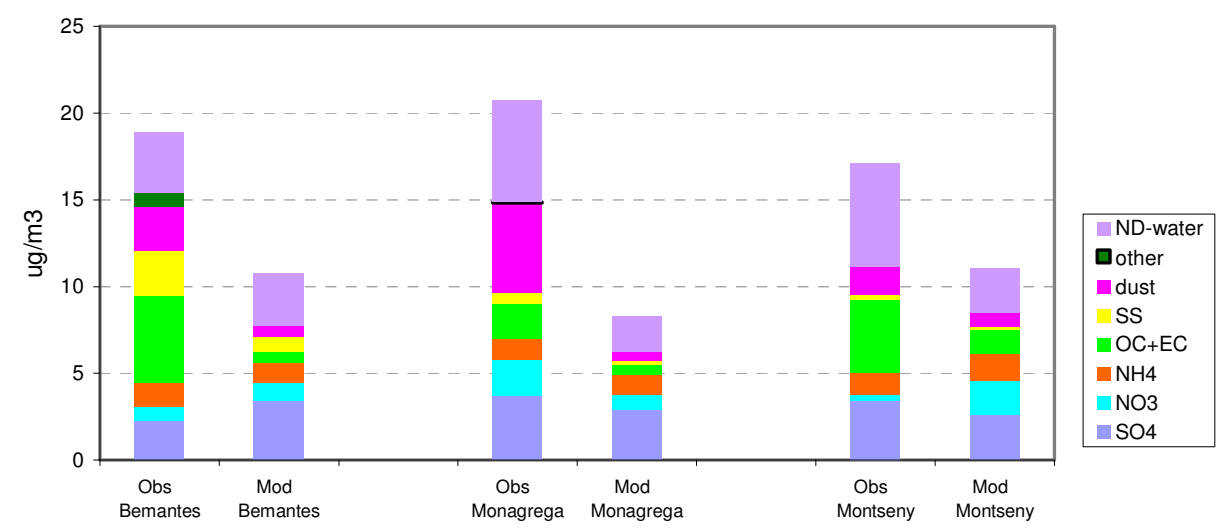

PM10, Birkenes, 2001
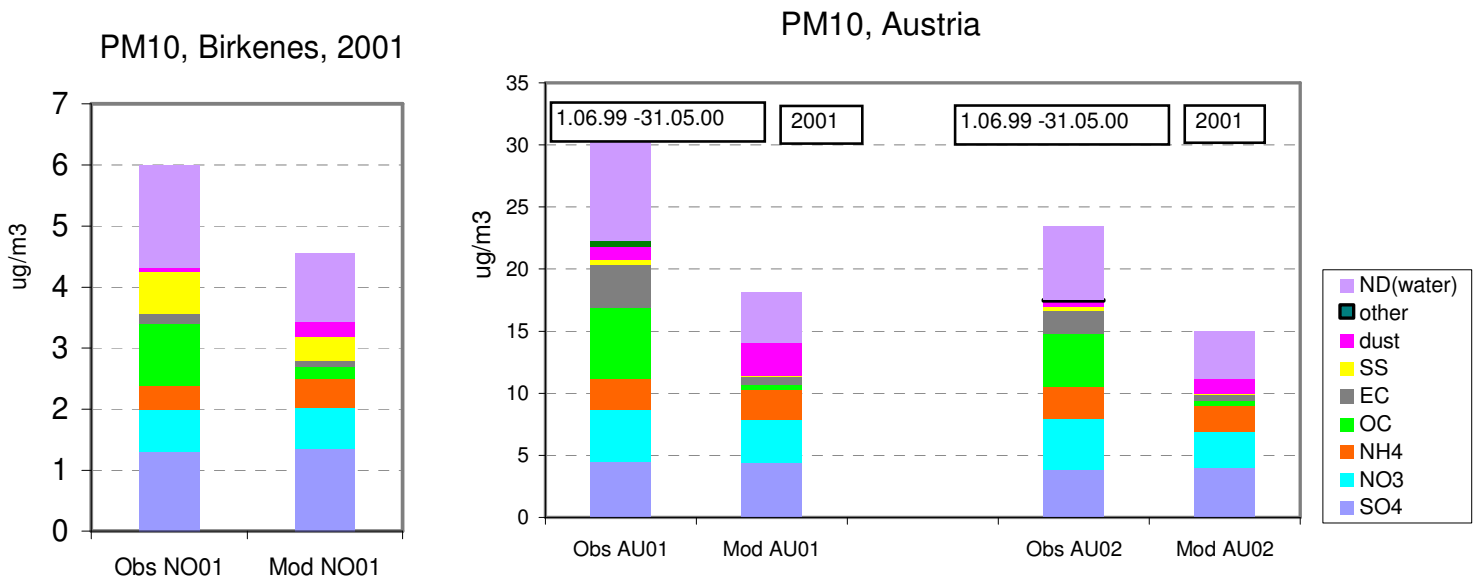

Fig. 3. Model calculated and measured chemical composition of $\mathrm{PM}_{10}\left(\mathrm{PM}_{2.5}\right.$ at Montseny). Here, ND means "not determined PM mass" in measurements and "water" is model calculated particle water (see also explanations in the text).

averaged over the period 1 January-31 May 2000, is shown in Fig. 4.

Similar to results for $\mathrm{PM}_{10}$ shown in Fig. 3, the largest discrepancy in $\mathrm{PM}_{2.5}$ composition between model results and measurements is found for carbonaceous particles (Fig. 3), especially for EC, whereas model fine OC compares better with measurements than $\mathrm{OC}$ in $\mathrm{PM}_{10}$. The larger underes- timation of OC mass in $\mathrm{PM}_{10}$ is probably due to coarse organic particles, which are not fully represented in the model. At these sites, about $30 \%$ of measured organic carbon was found in the coarse mode and was to a certain level attributed to primary biogenic organic aerosol (Puxbaum et al., 2003), which is not included in the model. 
PM2.5 chemical composition, Austria

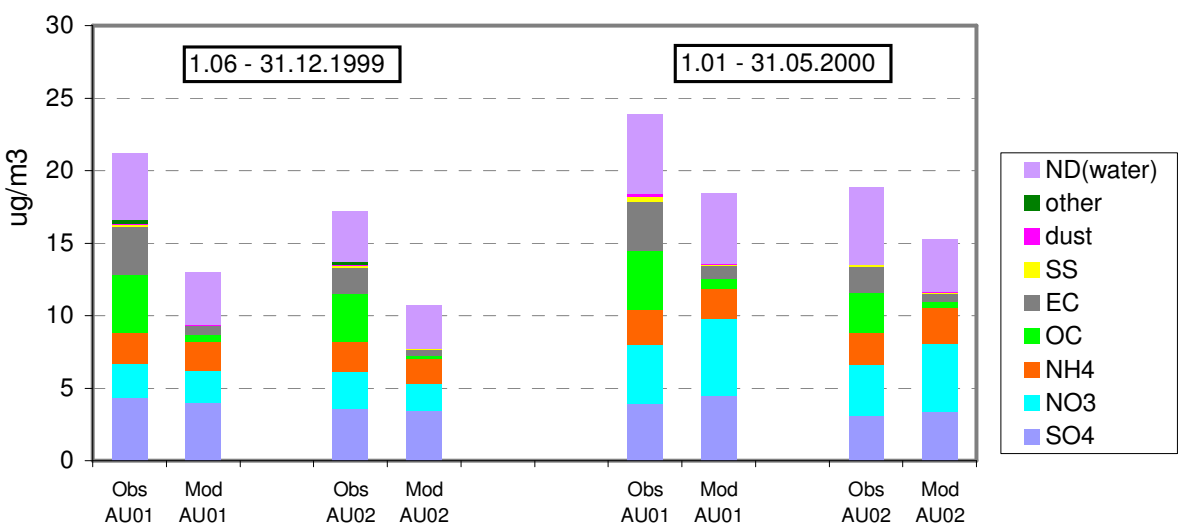

Fig. 4. Modelled and measured chemical composition of $\mathrm{PM}_{2.5}$ at Austrian sites: AU01 (Vienna) and AU02 (Streithofen) averaged over periods 1 June-31 December 1999 and 1 January-31 May 2000.

Model calculated concentrations of the main $\mathrm{PM}_{2.5}$ soluble components, $\mathrm{SO}_{4}^{2-}, \mathrm{NO}_{3}^{-}$and $\mathrm{NH}_{4}^{+}$, compare reasonably well with measurements (Fig. A1 in Appendix). The temporal correlation coefficients $(\mathrm{R})$ for daily concentrations in 1999 and 2000 periods vary from 0.54 to 0.56 for $\mathrm{SO}_{4}^{2-}$, from 0.59 to 0.69 for $\mathrm{NO}_{3}^{-}$, from 0.62 to 0.68 for $\mathrm{NH}_{4}^{+}$ and from 0.3 to 0.62 for sea salt. The total mass of SIA is simulated correctly by the model; however there are slight discrepancies between calculated and observed contributions of the individual inorganic components. On average, the model slightly underestimates measured sulphate and ammonium concentrations in 1999 and overestimates those in 2000. Calculated average nitrate concentrations are very close to measurements in 1999 and overestimated by about $25-30 \%$ in 2000. For 1999, sea salt is under-predicted by the model, while calculations for 2000 are rather close to measurements. Based on these verification results for main hygroscopic components it can be expected that model calculations should give a reasonable estimate of water in measured $\mathrm{PM}_{2.5}$ mass.

A rather good correspondence has been found between calculated residual aerosol water and unaccounted $\mathrm{PM}_{2.5}$ mass in 2000 (Fig. 5), with the correlation coefficients R of 0.45 and 0.57 at Vienna and Streithofen sites respectively. On the other hand, for 1999 the corresponding correlation coefficients are 0.32 and 0.17 . Notably, the correlations between unaccounted $\mathrm{PM}_{2.5}$ mass and the measured mass of soluble $\mathrm{PM}_{2.5}$ components (SIA and sea salt) in 2000 are much higher (0.62 at AU01 and 0.63 at AU02) than in 1999 (0.37 at AU01 and 0.35 at AU02). This may indicate that in 1999 the unaccounted PM mass was to a larger degree associated with other factors than particle water. In a number of days in 1999, the mass of undetermined $\mathrm{PM}_{2.5}$ drops below zero, which could be attributed to the measurement/analysis uncertainties. Averaged over the whole period, the mass of model calculated residual water is smaller than the mass of $\mathrm{PM}_{2.5}$ undetermined fraction. However, on some days the model calculated mass of $\mathrm{PM}_{2.5}$ water exceeds the unaccounted $\mathrm{PM}_{2.5}$ mass. The careful study of calculation results has revealed that on those days the model overestimates the concentrations of one or several soluble $\mathrm{PM}_{2.5}$ constituents, which consequently results in overestimation of aerosol water.

As pointed out above, the contribution to organic aerosol mass from elements other than carbon (e.g. hydrogen, oxygen, nitrogen) can be one of the sources of unaccounted PM mass in measurements, if OC mass in the identified PM fraction is presented as mass of carbon. In Puxbaum et al. (2003), the factors for conversion of organic carbon mass to organic matter $(\mathrm{OM})$ mass of 1.3 and 1.7 were considered appropriate for respectively urban (the Vienna site) and rural (the Streithofen site) environments. We have used those conversion factors to derive the total mass of organic aerosol (i.e. OM) in $\mathrm{PM}_{2.5}$ and thus account for the unaccounted part of $\mathrm{PM}_{2.5}$ due to non- $\mathrm{C}$ atoms in organic particles. Then, the unaccounted $\mathrm{PM}_{2.5}$ mass should be largely due to particle-bound water.

In this case (Fig. 6), the model calculated mass of residual water is somewhat larger than the undetermined $\mathrm{PM}_{2.5}$ mass and the correlation between them is slightly lowered compared to that in Fig. 5. The exceedance of unaccounted $\mathrm{PM}_{2.5}$ mass by the model calculated mass of particle water, seen in Fig. 6, could be both due to model over-prediction of aerosol water and/or due to the rather crude assumption on conversion factors from OC to OM. As described above, the model assumes that aerosols reside in a meta-stable aqueous form what corresponds the upper branch of water adsorptiondesorption curve. Therefore, the model will probably overestimate the aerosol water content in samples collected at relative humidity lower than $50 \%$. On the other hand, some 

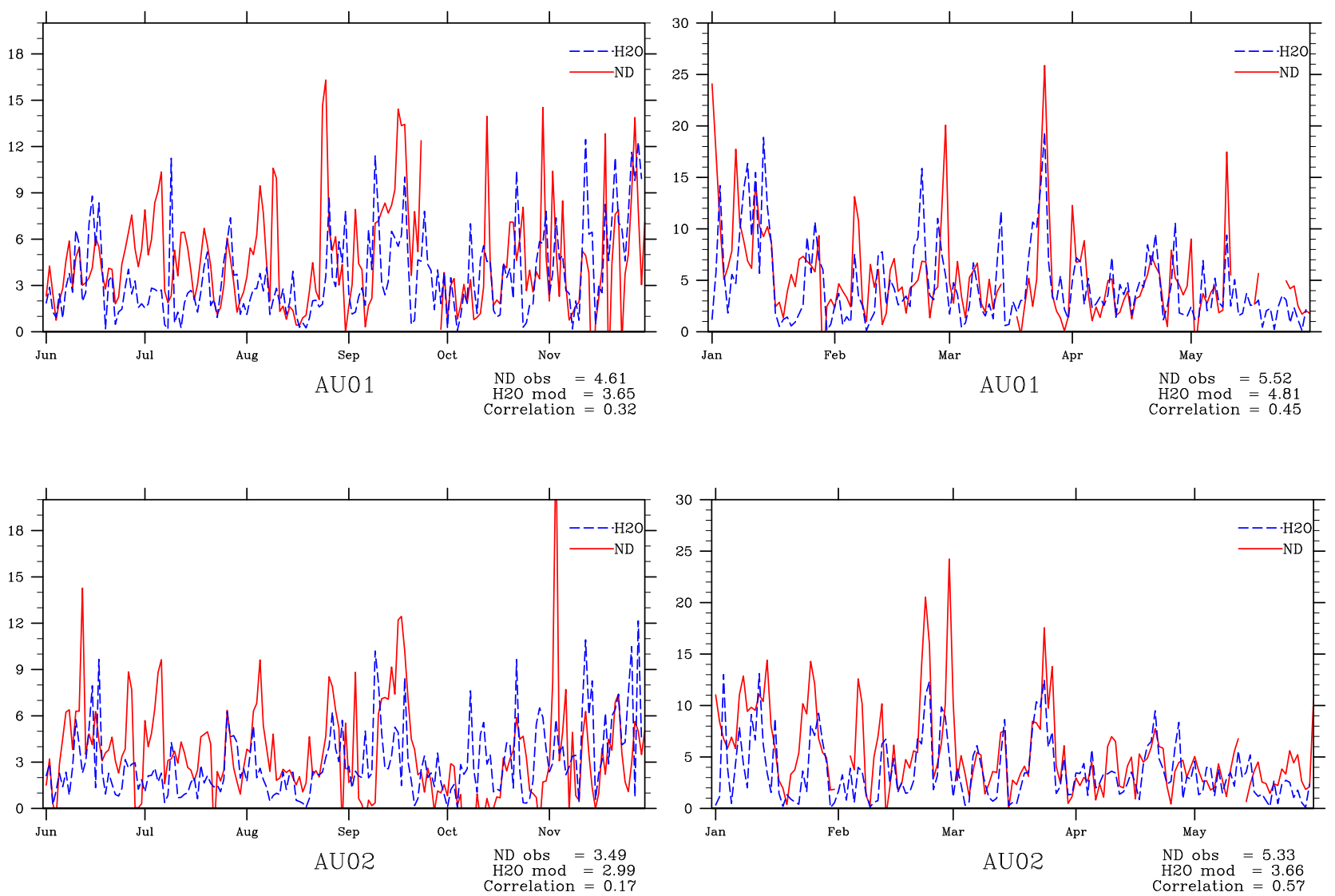

Fig. 5. Daily time-series of model calculated residual water in $\mathrm{PM}_{2.5}$ mass (blue dashed line) and the unaccounted (*) $\mathrm{PM} 2.5$ mass in measurements (red solid line) at AU01 and AU02 for the period 1 July 1999-1 June 2000. (*) Unaccounted part may include non-C atoms associated with organic aerosol.

underestimation of particle water is anticipated due to the model not accounting for the contribution of water associated with organic components Unfortunately, the measurement data at those sites were insufficient for more elaborate examination of the results.

As shown in Fig. 7, model calculated "wet" PM2.5 concentrations (i.e. including aerosol water) are closer to the observed levels of PM2.5. Moreover, the model accounting for aerosol water has somewhat improved the correlation between calculated and measured PM2.5. On the other hand, modelled "dry" PM2.5 concentrations agree quite well with the identified mass of measured PM2.5, i.e. the mass of all chemically identified components (Fig. 8).

Summarising, the correspondence, found between calculated particle water and the unaccounted fraction of gravimetric PM2.5 mass measured at the Austrian sites, supports a common explanation that a part of unaccounted PM2.5 mass is due to particle-bound water. According to our calculations, the unaccounted fraction of PM2.5 mass contains rather a considerable amount of water; however, there are indications that the model may overestimate particle water (Fig. 6). Moreover, there is a considerable daily variability of the difference between calculated PM2.5 water and PM2.5 unaccounted mass, which is probably due to random sampling artefacts affecting the fraction of unidentified PM mass.

\subsection{Comparison of model calculated wet $\mathrm{PM}_{10}$ and $\mathrm{PM}_{2.5}$ with EMEP observations}

$\mathrm{PM}_{10}$ and $\mathrm{PM}_{2.5}$ monitoring data from the EMEP data base have been used in the evaluation of EMEP model performance. Within the EMEP network, gravimetric methods for determining PM mass are employed at all stations. Therefore, it is reasonable to assume that measured $\mathrm{PM}_{2.5}$ and $\mathrm{PM}_{10}$ concentrations include particle-bound water.

To derive "wet" PM concentrations, model calculated residual particle water has been added to the dry PM mass. $\mathrm{PM}_{10}$ and $\mathrm{PM}_{2.5}$ concentrations including particle water are believed to be more consistent with $\mathrm{PM}_{10}$ and $\mathrm{PM}_{2.5}$ concentrations determined gravimetrically (or with the equivalent methods). Model calculated annual mean $\mathrm{PM}_{10}$ and $\mathrm{PM}_{2.5}$ concentrations have been compared with EMEP observations in 2000-2001. The bias in model calculated $\mathrm{PM}_{10}$ and $\mathrm{PM}_{2.5}$ concentrations, both dry and including particle water, as compared with measurements is shown in Table 3. 

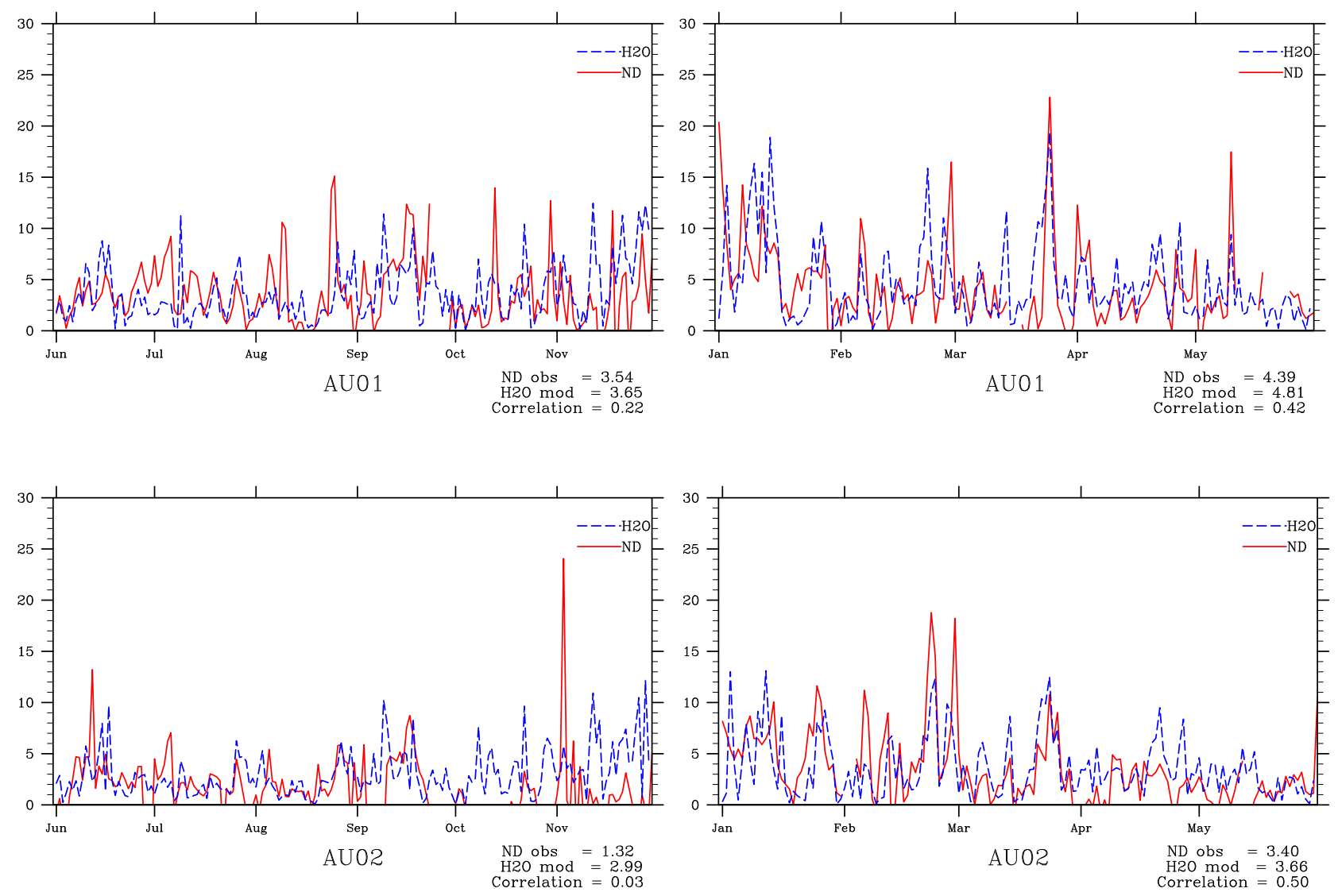

Fig. 6. Daily time-series of model calculated residual water in $\mathrm{PM}_{2.5}$ mass (blue dashed line) and the unaccounted (*) $\mathrm{PM}_{2.5}$ mass in measurements (red solid line) at AU01 and AU02 for the period 1 July 1999-1 June 2000. (*) OC is converted to OM and included in the identified part. Then, the unaccounted part is largely due to particle water.

As expected, accounting for residual water in calculated PM concentrations has decreased the model underestimation of measured $\mathrm{PM}_{10}$ and $\mathrm{PM}_{2.5}$. It can be noted that the larger negative bias in 2001 compared to 2000 is due to the considerable underestimation of $\mathrm{PM}_{10}$ concentrations by the model at Spanish sites, which were firstly reported in 2001. As it was explained above, the model not accounting for secondary organic aerosol and natural dust is a plausible reason for PM under-prediction in Spain.

Scatter-plots of calculated versus measured $\mathrm{PM}_{10}$ and $\mathrm{PM}_{2.5}$ concentrations at EMEP sites are presented in Fig. 9. The upper panels show results for modelled dry $\mathrm{PM}_{10}$ and $\mathrm{PM}_{2.5}$ concentrations and the lower panels show comparisons for wet $\mathrm{PM}_{10}$ and $\mathrm{PM}_{2.5}$, i.e. including aerosol water.

The scatter-plots show that calculated concentrations of PM including aerosol water agree better with the measured values, but the model still underestimates $\mathrm{PM}_{10}$ and $\mathrm{PM}_{2.5}$ at most of the sites. The underestimation is expected to be further reduced when all aerosol sources are included in the model. Overestimation by the model of annual mean $\mathrm{PM}_{10}$ and $\mathrm{PM}_{2.5}$ concentrations at several mountain sites (DE03, DE05, DE08, CH04 and CH05) is due to its overestima-
Table 3. The annual mean bias of model calculated $\mathrm{PM}_{10}$ and $\mathrm{PM}_{2.5}$, dry and including particle water (wet), as compared to EMEP measurements in 2000 and 2001.

\begin{tabular}{ccccc}
\hline & \multicolumn{2}{c}{ Bias for 2000 (\%) } & \multicolumn{2}{c}{ Bias for 2001 (\%) } \\
& Dry mass & Wet mass & Dry mass & Wet mass \\
\hline PM10 & -33 & -13 & -49 & -33 \\
PM2.5 & - & - & -43 & -24 \\
\hline
\end{tabular}

tion of winter aerosol concentrations at those sites, when they are in the free troposphere. The particle water content will be overestimated as a consequence of the overestimation of PM mass. Unfortunately, no appropriate measurements of PM individual components and water were available for further checking of the results (the only relevant data was $\mathrm{SO}_{4}$ measurements at DE03 (Schauinsland, Germany), which showed that the model overestimated sulphate for that site). As expected, the spatial correlation between modelled and measured $\mathrm{PM}_{10}$ and $\mathrm{PM}_{2.5}$ has not improved. 

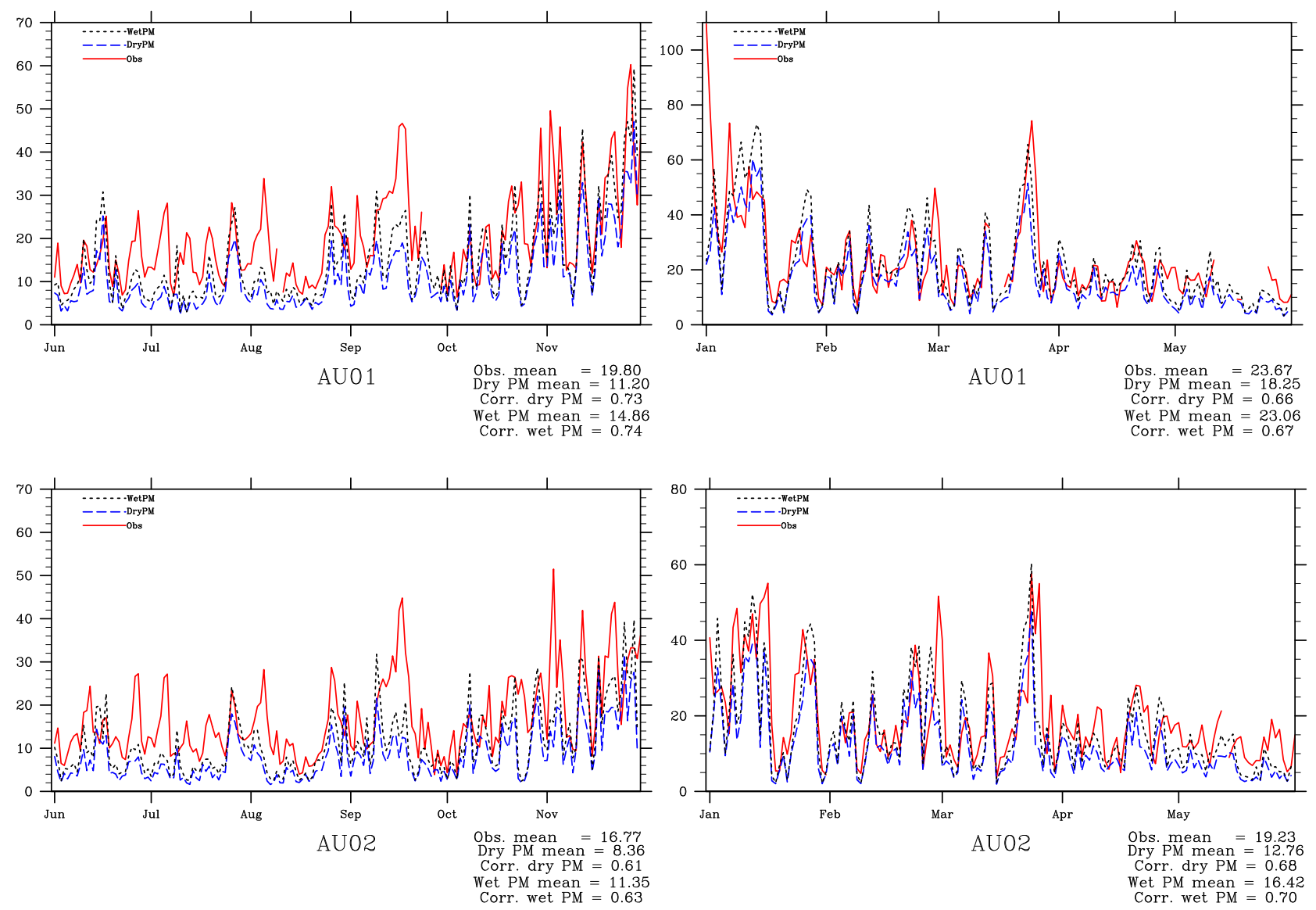

Fig. 7. Time-series of daily concentrations of model calculated dry $\mathrm{PM}_{2.5}$ mass (blue dashed line), wet $\mathrm{PM}_{2.5}$ (black dashed line) and measured $\mathrm{PM}_{2.5}$ (red solid line) at AU01 and AU02 for the period 1 July 1999-1 June 2000.

As expected, accounting for aerosol water in the model has not improved the spatial correlation between calculated and measured PM10 and PM2.5.

Comparison of modelled daily $\mathrm{PM}_{10}$ and $\mathrm{PM}_{2.5}$ with measurements at EMEP sites shows that accounting for particlebound water in calculated PM mass has resulted in certain improvement of the model results (Tables A1 and A2 in Appendix). Calculated $\mathrm{PM}_{10}$ and $\mathrm{PM}_{2.5}$ concentrations including aerosol water are closer to the measured values and the correlation at most of the stations is somewhat better compared to that for calculated dry PM. However at some Spanish sites, the correlation between model and measured $\mathrm{PM}_{10}$ and $\mathrm{PM}_{2.5}$ becomes slightly poorer when particle water in PM is accounted for. This can feasibly result from the model's inaccurate prediction of the daily variation of PM chemical composition and hence particle water content at those sites, which was impossible to check due to the lack of necessary measurements.

Another reason for worsened correlation between calculated wet PM and observations can be that aerosol water is calculated using the same conditions $\left(20^{\circ} \mathrm{C}\right.$ and $\left.50 \%\right)$ for all days and at all sites. Thus, the calculated aerosol water con- tent is determined solely by PM chemical composition, while particle water mass on dust loaded filters will also be affected by the differences in sampling procedures or transportation, storing and weighing of filters.

As a final comment, it is important to be wary of the origin of PM measurement data when deciding on comparison of either dry or wet PM concentrations with observations. Accounting for aerosol water in calculated PM concentrations is relevant when comparing model results with PM measurements at the stations where gravimetric (or equivalent) methods are used. One should be particularly careful when comparing model PM concentrations with the readings from TEOM and Beta-instruments, corrected for the losses of semi-volatile components in order to assure the comparability of those measurements with reference gravimetric method. Actually, comparison of calculated wet PM concentrations with the corrected PM mass from automated instruments is not physically justified. If feasible, it is more appropriate to compare calculated dry PM concentrations with PM concentrations measured with automated instruments, in which aerosol water is removed from the sample. 

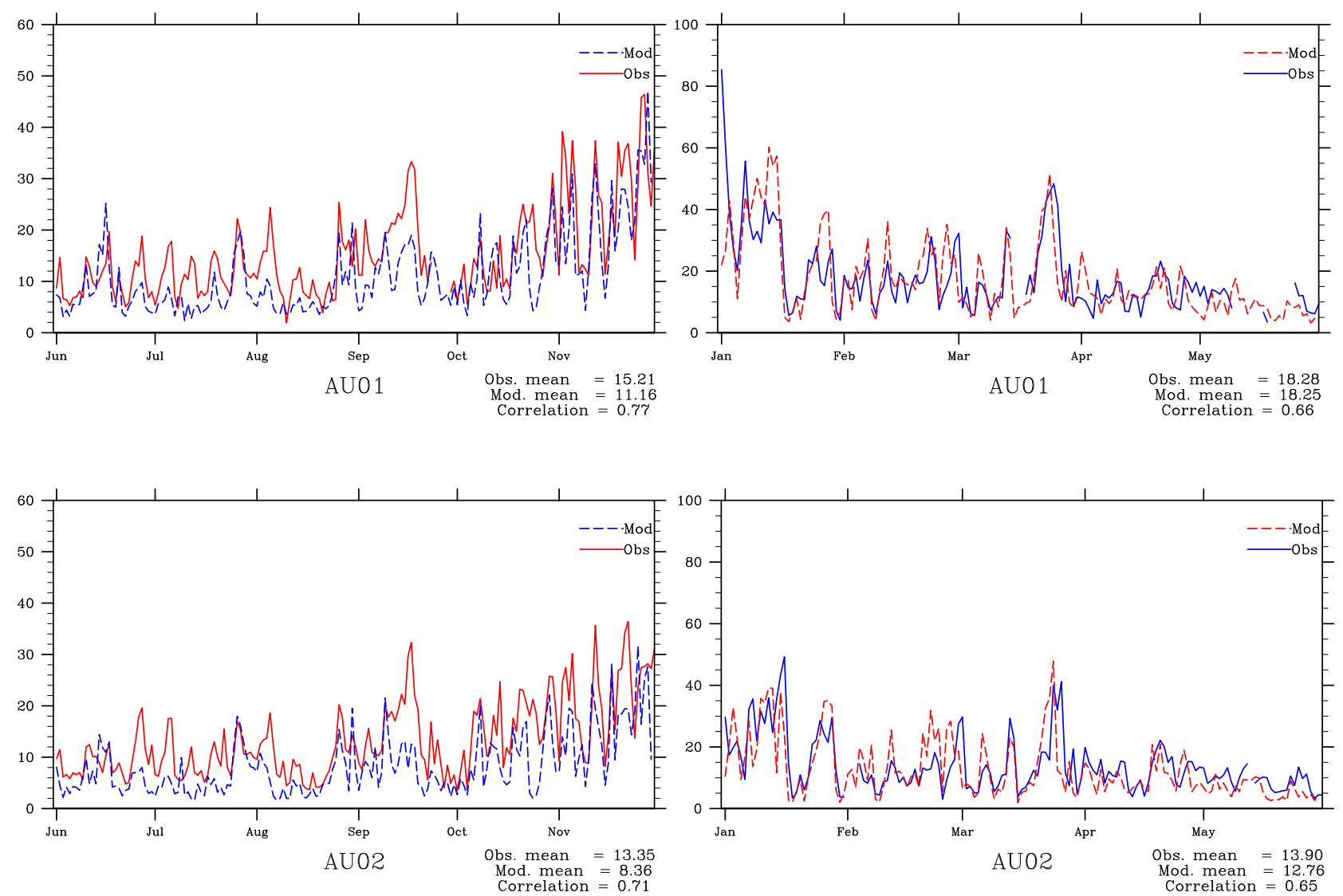

Fig. 8. Time-series of daily concentrations of model calculated dry $\mathrm{PM}_{2.5}$ mass (blue dashed line) and the identified $\mathrm{PM}_{2.5}$ mass in measurements (red solid line) at AU01 and AU02 for the period 1 July 1999-1 June 2000.

\section{Conclusions}

In this work, we have addressed the issue of particle-bound water in gravimetrically measured PM mass. Available data on PM chemical analyses show that significant fractions of $\mathrm{PM}_{2.5}$ and $\mathrm{PM}_{10}$ mass remain unidentified. The EMEP aerosol model has been used to estimate to what extent particle water can explain the unaccounted PM mass. We also examine to what extend the particle water can explain discrepancies between modelled and gravimetrically measured $\mathrm{PM}_{10}$ and $\mathrm{PM}_{2.5}$. For this purpose, we attempt to account for particle water in model calculated PM concentrations to assure their more consistent comparison with observations.

The mass of aerosol water in $\mathrm{PM}_{10}$ and $\mathrm{PM}_{2.5}$ concentrations has been calculated with the aerosol model for filter calibration conditions required by CEN standard (i.e. $50 \% \mathrm{RH}$ and temperature $20^{\circ} \mathrm{C}$ ). The calculated annual mean fraction of water in $\mathrm{PM}_{10}$ and $\mathrm{PM}_{2.5}$ varies between 20 and $35 \%$ over Europe, depending on the mass and the type of mixture of soluble PM components. At 6 stations in Austria, Norway and Spain, where data on $\mathrm{PM}_{10}$ or $\mathrm{PM}_{2.5}$ chemical composition was available, the model estimates that particle water can explain between 30 and $80 \%$ of the unaccounted mass in measured $\mathrm{PM}_{10}$ and $\mathrm{PM}_{2.5}$ concentrations. In this case, a part of the unaccounted PM mass consists of non-C atoms associated with organic aerosol, as measured organic carbon were not converted to organic matter because molecular-to-carbon mass ratios were unknown.

Model calculations have been tested with data at two Austrian stations in Vienna and Streithofen, where daily data on $\mathrm{PM}_{2.5}$ chemical composition was available for the period 1 June 1999-31 May 2000. The temporal correlation coefficients between calculated aerosol water and unaccounted $\mathrm{PM}_{2.5}$ mass are respectively 0.45 and 0.57 in 2000 , what suggests that aerosol water is responsible for a significant part of the unaccounted $\mathrm{PM}_{2.5}$ mass at those sites. On the other hand, during the measurement period in 1999, when factors other than particle water appear to determine the unaccounted $\mathrm{PM}_{2.5}$ mass, the correlation between calculated aerosol water and undetermined mass is much lower $(R=0.35$ and 0.17).

According to our model estimates, particle water explains up to $75-80 \%$ of undermined $\mathrm{PM}_{2.5}$ fraction at the Austrian sites. If organic carbon mass is converted to organic matter 

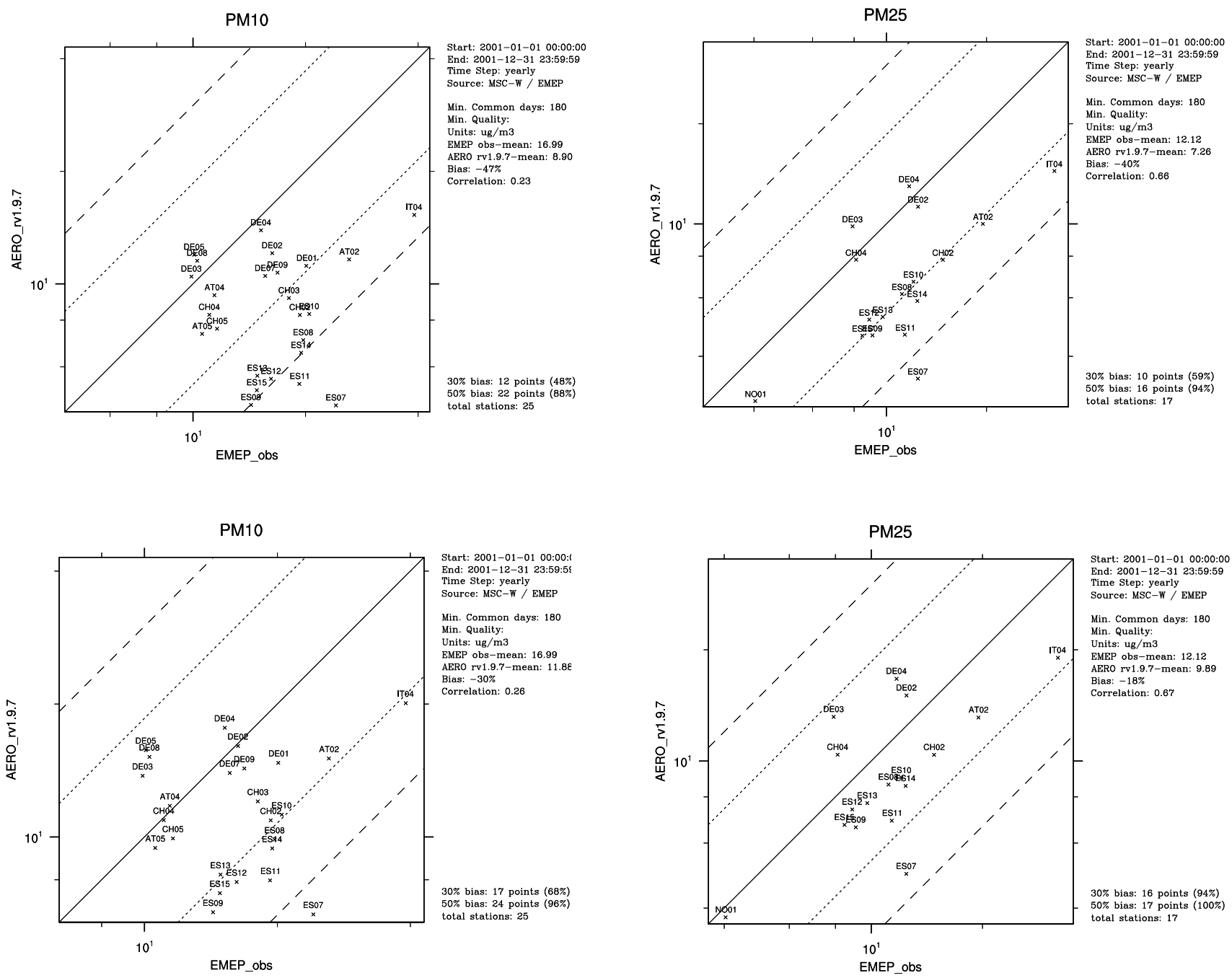

Fig. 9. Scatter-plots for $\mathrm{PM}_{10}$ and $\mathrm{PM}_{2.5}$ monitored at EMEP sites in 2001 versus model calculated: dry $\mathrm{PM}_{10}$ and $\mathrm{PM}_{2.5}$ (upper panel) and $\mathrm{PM}_{10}$ and $\mathrm{PM}_{2.5}$ with particle water accounted for (lower panel).

Start: 2001-01-01 00:00:t End: $2001-12-31$ 23:59:5
Time Step: yearly Source: MSC-W / EMEP Min. Common days: 180 Min. Quality: EMEP obs-mean: 16.99 AERO rv1.9.7-mean: 11.8 Bias: $-30 \%$
Correlation: 0.26

$30 \%$ bias: 17 points $(68 \%)$ (1) points (96\%)

\section{PM10 chemical composition}

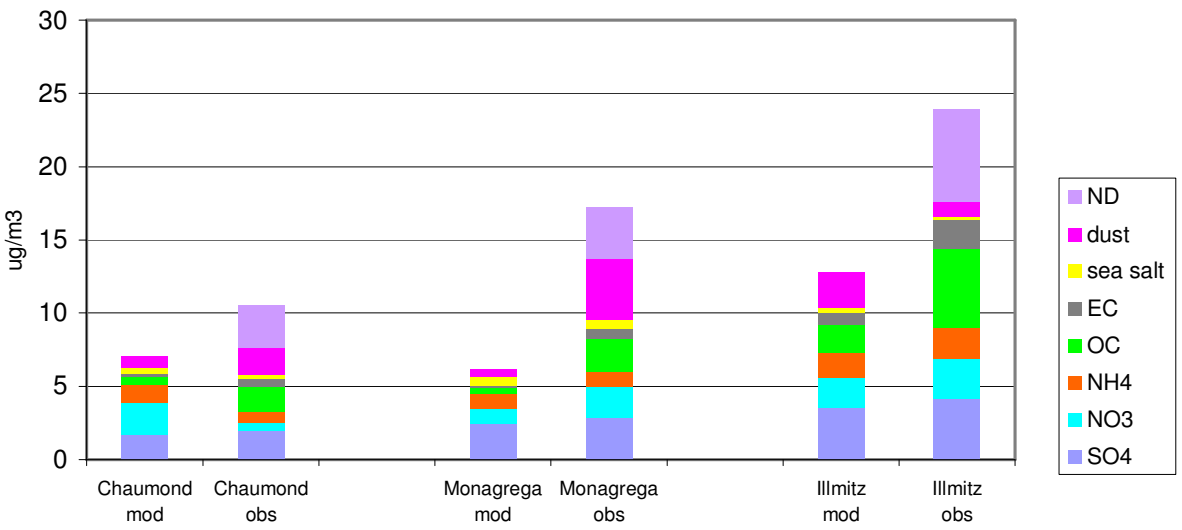

Fig. A1. Comparison of model calculated daily concentrations of secondary inorganic aerosols with observations at AU01 (Vienna) for the period 1 June 1999-31 May 2000. Units: $\mu \mathrm{g} / \mathrm{m}^{3}$. 

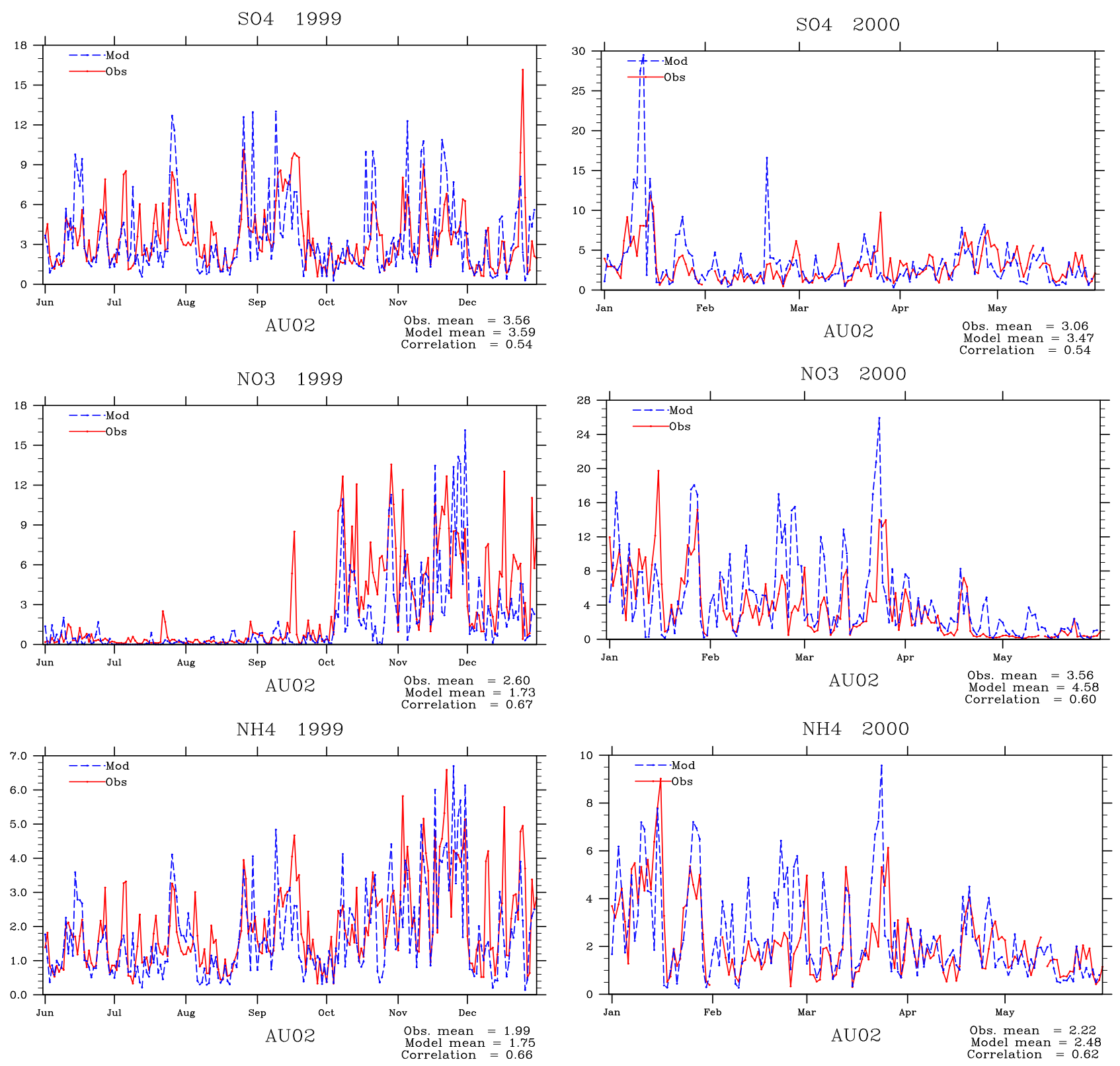

Fig. A2. Comparison of model calculated daily concentrations of secondary inorganic aerosols with observations at AU02 (Streithofen) for the period 1 June 1999-31 May 2000. Units: $\mu \mathrm{g} / \mathrm{m}^{3}$.

mass, the calculated water exceeds unaccounted PM2.5 mass in some days. It can probably be due to overestimation of molecular-to-carbon mass ratio in those days. It is also pointed out that due to the assumption that aerosols exist in a liquid phase, the model may overestimate the aerosol water content in PM samples collected at low relative humidity conditions. On the other hand, the contribution from water associated with organic aerosols has not been included in the calculations. Unfortunately, the proper validation of model calculated PM water content was unfeasible as no measurements of particle water were available at those sites.
Furthermore, it is shown that at both of the Austrian sites calculated daily $\mathrm{PM}_{2.5}$ concentrations agree better with measurements when the model accounts for aerosol water in PM mass, both with respect to mean values and temporal correlations. These results suggest that particle water should be taken in to account when comparing model calculated PM with gravimetrically measured PM mass. It should also be pointed out that the calculated dry $\mathrm{PM}_{2.5}$ mass is found to agree rather well with the $\mathrm{PM}_{2.5}$ identified mass measured at Austrian sites, which strengthens the trust in the general model performance. 
Table A1. Validation of model calculated daily $\mathrm{PM}_{10}$ concentrations $\left(\mu \mathrm{g} / \mathrm{m}^{3}\right)$ against measurements at EMEP stations in 2001 : for dry $\mathrm{PM}_{10}$ and wet $\mathrm{PM}_{10}$.

\begin{tabular}{lcccccc}
\hline Sites & $\begin{array}{c}\text { Obs. } \\
\text { Mean }\end{array}$ & $\begin{array}{c}\text { Mod. mean } \\
\text { dry PM }\end{array}$ & $\begin{array}{c}\text { Corr. }(R) \\
\text { dry PM }\end{array}$ 10 & $\begin{array}{c}\text { Mod. mean } \\
\text { PM }_{10}+\text { water }\end{array}$ & $\begin{array}{c}\text { Corr. }(R) \\
\text { PM }_{10}+\text { water }\end{array}$ \\
\hline DE01 & Westerland & 20.13 & 10.48 & 0.76 & 13.16 & 0.77 \\
DE02 & Langenbrügge & 16.30 & 11.41 & 0.66 & 15.02 & 0.68 \\
DE03 & Schauinsland & 9.92 & 9.88 & 0.23 & 12.89 & 0.27 \\
DE04 & Deuselbach & 15.21 & 11.22 & 0.51 & 14.58 & 0.55 \\
DE05 & Brotjacklriegel & 10.08 & 11.74 & 0.19 & 15.29 & 0.21 \\
DE07 & Neuglobsow & 15.62 & 9.82 & 0.69 & 12.95 & 0.71 \\
DE08 & Schmücke & 10.26 & 11.15 & 0.20 & 14.48 & 0.22 \\
DE09 & Zingst & 16.86 & 9.99 & 0.77 & 12.96 & 0.81 \\
CH02 & Payerne & 19.34 & 8.23 & 0.45 & 10.63 & 0.46 \\
CH03 & Taenikon & 18.06 & 9.00 & 0.50 & 11.68 & 0.51 \\
CH04 & Chaumont & 11.08 & 8.24 & 0.37 & 10.65 & 0.42 \\
CH05 & Rigi & 11.61 & 7.48 & 0.46 & 9.61 & 0.50 \\
AT02 & Illmitz & 26.21 & 11.05 & 0.59 & 14.30 & 0.59 \\
AT04 & St. Koloman & 11.42 & 9.49 & 0.28 & 11.77 & 0.33 \\
AT05 & Vorhegg & 10.60 & 7.08 & 0.40 & 8.95 & 0.48 \\
IT04 & Ispra & 39.06 & 14.00 & 0.45 & 17.43 & 0.44 \\
ES07 & Viznar & 24.17 & 5.44 & 0.41 & 6.76 & 0.35 \\
ES08 & Niembro & 19.72 & 6.67 & 0.27 & 9.10 & 0.21 \\
ES09 & Campisabalos & 14.20 & 4.85 & 0.15 & 6.67 & 0.17 \\
ES10 & Cabo de Creus & 20.48 & 7.33 & 0.20 & 9.17 & 0.18 \\
ES11 & Barcarrota & 19.15 & 5.67 & 0.42 & 7.65 & 0.36 \\
ES12 & Zarra & 16.18 & 5.40 & 0.26 & 7.23 & 0.27 \\
ES13 & Penausende & 14.59 & 5.73 & 0.31 & 7.90 & 0.30 \\
ES14 & Els Torms & 19.48 & 6.45 & 0.39 & 8.66 & 0.41 \\
ES15 & Risco Llano & 14.82 & 5.55 & 0.02 & 7.40 & -0.01 \\
NO01 & Birkenes & 6.08 & 3.38 & 0.50 & 4.38 & 0.51 \\
\hline & & & & & & \\
\hline
\end{tabular}

Table A2. Validation of model calculated daily $\mathrm{PM}_{2.5}$ concentrations $\left(\mu \mathrm{g} / \mathrm{m}^{3}\right)$ against measurements at EMEP stations in 2001 : for dry $\mathrm{PM}_{2.5}$ and wet $\mathrm{PM}_{2.5}$.

\begin{tabular}{lcccccc}
\hline Sites & $\begin{array}{c}\text { Obs. } \\
\text { Mean }\end{array}$ & $\begin{array}{c}\text { Mod. mean } \\
\text { dry } \text { PM }_{2.5}\end{array}$ & $\begin{array}{c}\text { Corr. }(R) \\
\text { dry PM }\end{array} .5$ & $\begin{array}{c}\text { Mod. mean } \\
\text { PM }_{2.5}+\text { water }\end{array}$ & $\begin{array}{c}\text { Corr. }(R) \\
\text { PM }_{2.5}+\text { water }\end{array}$ \\
\hline AT02 & Illmitz & 19.54 & 9.61 & 0.56 & 12.57 & 0.56 \\
DE02 & Langenbrügge & 12.46 & 10.69 & 0.68 & 14.25 & 0.69 \\
DE03 & Schauinsland & 7.93 & 9.22 & 0.12 & 12.30 & 0.15 \\
DE04 & Deuselbach & 11.71 & 10.77 & 0.56 & 14.17 & 0.59 \\
CH02 & Payerne & 14.80 & 7.45 & 0.46 & 9.85 & 0.47 \\
CH04 & Chaumont & 8.12 & 7.46 & 0.36 & 9.87 & 0.41 \\
IT04 & Ispra & 32.01 & 12.91 & 0.43 & 16.32 & 0.42 \\
ES07 & Viznar & 12.46 & 3.98 & 0.39 & 5.30 & 0.37 \\
ES08 & Niembro & 11.16 & 5.82 & 0.41 & 8.18 & 0.34 \\
ES09 & Campisabalos & 9.02 & 4.68 & 0.19 & 6.58 & 0.21 \\
ES10 & Cabo de Creus & 12.09 & 5.93 & 0.33 & 7.78 & 0.29 \\
ES11 & Barcarrota & 11.36 & 4.82 & 0.44 & 6.80 & 0.39 \\
ES12 & Zarra & 8.89 & 4.97 & 0.38 & 6.82 & 0.40 \\
ES13 & Penausende & 9.70 & 5.25 & 0.46 & 7.46 & 0.46 \\
ES14 & Els Torms & 12.41 & 5.79 & 0.49 & 7.99 & 0.50 \\
ES15 & Risco Llano & 8.46 & 4.87 & 0.08 & 6.67 & 0.05 \\
NO01 & Birkenes & 4.04 & 2.59 & 0.55 & 3.39 & 0.55 \\
\hline
\end{tabular}


Finally, model calculated $\mathrm{PM}_{10}$ and $\mathrm{PM}_{2.5}$ concentrations including aerosol water have been compared with PM measurements from the EMEP database. Accounting for aerosol water in calculated $\mathrm{PM}_{10}$ and $\mathrm{PM}_{2.5}$ has considerably reduced the model underestimation of measured $\mathrm{PM}_{10}$ and $\mathrm{PM}_{2.5}$ concentrations, as compared with the previous verification results for model calculated dry PM concentrations. Compared with measurements at EMEP sites in 2000 and 2001, model underestimation of annual mean $\mathrm{PM}_{10}$ has decreased from $33-56 \%$ to $13-42 \%$, and of annual mean $\mathrm{PM}_{2.5}$ from 43 to $24 \%$. Another important result is that the model accounting for particle water has increased the temporal correlation between calculated and measured daily $\mathrm{PM}_{10}$ and $\mathrm{PM}_{2.5}$ concentrations at most of the EMEP sites. The exception is Spanish sites where the effect of wind blown dust would need to be accounted for in order to improve the model PM calculations.

Summing up, is has been shown that accounting for particle water in modelled PM could explain a half of the model underestimation of $\mathrm{PM}_{10}$ and $\mathrm{PM}_{2.5}$ in comparison with gravimetric measurements. However, there are caveats to the model estimates of particle-bound water as no verification of the calculated water content is presently available due to the lack of measurement data. Verification of particle water calculations in the EMEP aerosol model will be carried out as new measurements of PM chemical composition, particle water and PM mass at different relative humidity become available.

Acknowledgements. We are grateful to S. Metzger for providing EMEP/MSC-W with the EQSAM model. Measurements on PM chemical composition were made available to us from the Austrian AUPHEP project and from database of the Spanish Ministry of Environment. The author particularly thanks L. Tarrasón, H. Fagerli and D. Simpson at the Norwegian Meteorological Institute for the constructive discussions during this work and for their comments on the draft version of the manuscript.

Edited by: J. Brandt

\section{References}

Andersson-Sköld, Y. and Simpson, D.: Secondary organic aerosol formation in Northern Europe: a model study, J. Geophys. Res., 106 (D7), 7357-7374, 2001.

Balasubramanian, R., Qian, W.-B., Decesari, S., Facchini, M. C., and Fuzzi, S.: Comprehensive characterisation of $\mathrm{PM}_{2.5}$ aerosols in Singapore, J. Geophys. Res., 108, D16, 4523, doi:10.1029/2002JD002517, 2003.

Berndt, T., Böge, O., Conrath, T., Stratmann, F., and Heintzenberg, J.: Formation of new particles in the system $\mathrm{H} 2 \mathrm{SO} 4(\mathrm{SO} 3) / \mathrm{H} 2 \mathrm{O} /(\mathrm{NH} 3)$ - first results from a flow-tube study, J. Aerosol Sci., 31, Suppl. 1, S554-S555, 2000.

Chang, C. T. and Tsai, C. J.: A model for the relative humidity effect on the reading of the $\mathrm{PM}_{10}$ beta-gauge monitor, J. Aerosol Science, 34, 1685-1697, 2003.
Chang, C. T., Tsai, C. J., Lee, C. T., Chang, S. Y., Cheng, M. T., and Cheng, H. M.: Differences in $\mathrm{PM}_{10}$ concentrations measured by beta-gauge monitor and hi-vol sampler, Atmos. Environ., 35, 5741-5748, 2001

EC: Council Directive 1999/30/EC of April 1999 relating to limit values for sulphur dioxide, nitrogen dioxide and oxides of nitrogen, particulate matter and lead in ambient air, available on: http://europa.eu.int/comm/environment/air/ambient.htm, Official Journal L 163, 0041-0060, 1999.

EMEP/CCC: EMEP Manual for Sampling and Analysis, EMEP/CCC Report 1/95, Revision, http://www.nilu.no/ projects/ccc/manual/index.html, 2001.

EN 12341: Air Quality - Determination of the $\mathrm{PM}_{10}$ fraction of suspended particular matter - Reference method and field test procedure to demonstrate equivalence of measurement methods, 1998.

Fitzgerald, J. W.: Dependence on the supersaturation spectrum of $\mathrm{CCN}$ on aerosol size distribution and composition, J. Atmos. Sci., 30, 628-634, 1973.

Matta, E., Facchini, M. c., Decesari, S., Mirce, M., Cavalli, F., Fuzzi, S., Putaud, J.-P., and Dell'Acqua, A.: Mass closure on the chemical species in size-seggregated atmospheric aerosol collected in an urban are of Po Valley, Italy, Atmos. Chem. Phys., 3, 623-637, 2003,

\section{SRef-ID: 1680-7324/acp/2003-3-623}

Metzger, S.: Gas/Aerosol partitioning: a simplified method for global modelling, PhD thesis, University Utrecht, http://www. library.uu.nl/digiarchief/dip/diss/1930853/inhoud.htm, 2000.

Metzger, S., Dentener, F., Pandis, S., and Lelieveld, J.: Gas/Aerosol Partitioning 1: A computationally efficient model, J. Geophys. Res., 107 (D16), 10.1029/2001JD001102, 2002a.

Metzger, S., Dentener, F., Krol, M., Jeuken, A., and Lelieveld, J.: Gas/aerosol partitioning 2. Global modeling results, J. Geophys. Res., 107 (D16), 10.1029/2001JD001103, 2002b.

Monahan, E. C., Spiel, D. E., and Davidson, K. L.: A model of marine aerosol generation via white caps and wave disruption, in: Oceanic Whitecaps, edited by: Monahan, E. C. and Macniochaill, G., Dordrecht, Reidel, 167-193, 1986.

Mårtensson, E. M., Nilsson, E. D., de Leeuw, G., Cohen, L. H., and Hansson, H.-C.: Laboratory simulations and parameterisation of the primary marine aerosol production, J. Geophys. Res., 108 (D9), doi:10.1029/2002JD002263, 2003.

Neusüß, C., Wex, H., Birmili, W., Wiedensohler, A., Koziar, C., Busch, B., Brüggemann, E., Gnauk, T., Ebert, M., and Covert, D. S.: Characterization and parameterization of atmospheric aerosol number-, mass-, and chemical size distributions in central Europe during LACE 98 and MINT, J. Geophys. Res., 107 (D21), 10.1029/2000JD000514, 2002.

Pirjola, L., Tsyro, S. G., Tarrason, L., and Kulmala, M.: A monodisprse aerosol dynamics module, apromising candidate for use in long-range transport models: Box model tests, J. Geophys. Res., 108, D9, 4258, doi:10.1029/2002JD002867, 2003.

Putaud, J.-P., Van Dingenen, R., DellAcqua, A., Raes, F., Matta, E., Decesari, S., Facchini, M. C., and Fuzzi, S.: Size-segregated aerosol mass closure and chemical composition in Monte cimon (I) during MINATROC. Atmos. Chem. Phys., 4, 889-902, 2004.

Putaud, J.-P., Raes, F., Van Dingenen, R., Brüggemann, E., Faccini, M.-C., Decesari, S., Fuzzi, S., Gehrig, R., Hüglin, S., Laj, P., Lorbeer, G., Maenhaut, W., Mihalopoulos, N., Müller, K., 
Querol, X., Rodriguez, S., Schneider, J., Spindler, G., ten Brink, H., Tørseth, K., and Wiedensohler, A.: A European Aerosol Phenomenology - 2: chemical characteristics of particulate matter at kerbside, urban, rural, and background sites in Europe, Atmos. Environ., 38, 2579-2595, 2004.

Puxbaum, H., Gomišèek, B., Kalina, M., Bauer, H., Salam, A., Stopper, S., Preining, O., and Hauck, H.: A dual site study of PM2.5 and PM10 aerosol chemistry in the larger region of Vienna, Austria, Atmos. Environ., 38, 3903-4089, 2004.

Rodríguez, S., Querol, X., Alastuey, A., Kallos, G., and Kakaliagoi, O.: Saharan dust contributions to $\mathrm{PM}_{10}$ and TSP levels in Southern and Eastern Spain, Atmos. Environ., 35, 2433-2447, 2001.

Rodríguez, S., Querol, X., Alastuey, A., and Plana, F.: Sources and processes affecting levels and composition of atmospheric aerosol the western Mediterranean, J. Geophys. Res., 107, D24, 4777, doi:10.1029/2001JD001488, 2002.

Schwela, D., Morawska, L., and Kotzias, D. (Eds): Guidelines for Concentrations and Exposure-Response Measurement of Fine and Ultra Fine Particulate Matter for use in Epidemiological Studies, EC JRC \& WHO, EUR 20238 EN, 2002.

Simpson, D., Fagerli, H., Jonson, J. E., Tsyro, S. G., Wind, P., and Tuovinen, J.-P.: Transboundary Acidification, Eutrophication and Ground Level Ozone in Europe, Part I. Unified EMEP Model Description. EMEP/MSC-W Status report 1/2003 Part I, Norwegian Meteorological Institute, Oslo, Norway, http://www. emep.int, 2003.

Simpson, D. and Makar, P.: Modelling SOA and OC in Europe, In: Transboundary Particulate Matter in Europe, edited by Torseth, K., EMEP Status Report 4/2004, Norwegian Institute for Air Reseach, Kjeller, Norway, http://www.emep.int, 2004.

Stokes, R. H. and Robinson, R. A.: Interactions in aqueous nonelectrolyte solutions, 1. Solute solvent equilibria, J. Phys. Chem., 70, 2126-2123, 1966.

TNO: The Co-ordinated European Programme on Particulate Matter emission Inventories, Projections and Guidance (CEPMEIP) database (available at http://www.air.sk/tno/cepmeip/), 2001.

Tsyro, S. G.: First estimates of the effect of aerosol dynamics in the calculation of PM10 and PM2.5. EMEP/MSC-W Note 4/2002, Norwegian Meteorological Institute, Oslo, Norway, http://www. emep.int, 2002.

Tsyro, S. G.: Model performance for particulate matter. In: EMEP Status report 1/2003. Transboundary acidification, eutrophication and ground ozone level, Part II: Unified EMEP model performance. EMEP/MSC-W Status report 1/2003 Part II, Norwegian Meteorological Institute, Oslo, Norway, http://www.emep.int, 2003.
Tsyro, S. G.: Model assessment of particulate matter in Europe in 2002, In: Transboundary Particulate Matter in Europe, edited by Torseth, K., EMEP Status Report 4/2004, Norwegian Institute for Air Reseach, Kjeller, Norway http://www.emep.int, 2004.

Tsyro, S. G., Tarrasón, L., and Kahnert, M.: Physical characterisation of particulate matter across Europe in 2000 and 2001. In: Kahnert and Tarrason (eds.) Transboundary particulate matter in Europe. EMEP Status report 4/2003, EMEP/CCC \& MSC-W \& CIAM Status Report 4/2003, Norwegian Institute for Air Research, Kjeller, Norway, http://www.emep.int, 2003.

Vestreng, V.: Review and revision, Emission data reported to CRTAP. Oslo, Norwegian Meteorological Institute, EMEP Status Report 2003, Technical Report 2003, Meteorological Synthesizing Centre - West, Norwegian Meteorological Institute, Oslo, Norway, http://www.emep.int, 2003.

Warneck, P.: Chemistry of the natural Atmosphere, Academic Press, USA, 2000.

Winkler, P. and Junge, C. E.: The growth of atmospheric aerosol particles as a function of the relative humidity, Part 1, Method and measurements at different locations, J. Rech. Technology, 12, 822-826, 1972.

Yttri, K. E.: PM $_{10}$ mass concentrations at Birkenes during 2002, In: Measurements of particulate matter, edited by Kahnert, M., Status report 2003, EMEP/CCC Report 5/2003, Norwegian Institute for Air Research, Kjeller, Norway, http://www.emep.int, 2003.

Yttri, K. E. and Tørseth, K.: Chemical characterisation and mass concentration of ambient aerosol at the EMEP site in Birkenes (Southern Norway) - A one-year study, EMEP/CCC Report 4/2002, Norwegian Institute for Air Research, Kjeller, Norway, http://www.emep.int, 2002.

Zappoli, S., Andracchio, A. Fuzzi, S., Facchini, M. C., Gelencser, A., Kiss, G., krivacsy, Z., Molnar, A., Meszaros, E., Hansson, H.C., Rosman, K., and Zebuhr, Y.: Inorganic, organic and macromolecular components of fine aerosol in different areas of Europe in relation to their water solubility, Atmos. Environ., 33, 27332743, 1999.

Zdanovski, A. B.: New methods of calculating solubulities of electrolytes in multicomponent systems, Zhu. Fiz. Khim., 22, 1475$1485,1948$. 